\title{
Facial and body sexual dimorphism are not interconnected in the Maasai
}

\author{
Marina L. Butovskaya ${ }^{1,2,3^{*}} \mathbb{D}$, Victoria V. Rostovtseva ${ }^{1}$ and Anna A. Mezentseva ${ }^{1}$
}

\begin{abstract}
Background: In this paper, we investigate facial sexual dimorphism and its' association with body dimorphism in Maasai, the traditional seminomadic population of Tanzania. We discuss findings on other human populations and possible factors affecting the developmental processes in Maasai.

Methods: Full-face anthropological photographs were obtained from 305 Maasai (185 men, 120 women) aged 17-90 years. Facial shape was assessed combining geometric morphometrics and classical facial indices. Body parameters were measured directly using precise anthropological instruments.

Results: Sexual dimorphism in Maasai faces was low, sex explained 1.8\% of the total shape variance. However, male faces were relatively narrower and vertically prolonged, with slightly wider noses, narrower-set and lower eyebrows, wider mouths, and higher forehead hairline. The most sexually dimorphic regions of the face were the lower jaw and the nose. Facial width-to-height ratio (fWHR), measured in six known variants, revealed no significant sexual dimorphism. The allometric effects on facial traits were mostly related to the face growth, rather than the growth of the whole body (body height). Significant body dimorphism was demonstrated, men being significantly higher, with larger wrist diameter and hand grip strength, and women having higher BMI, hips circumferences, upper arm circumferences, triceps skinfolds. Facial and body sexual dimorphisms were not associated.
\end{abstract}

Conclusions: Facial sex differences in Maasai are very low, while on the contrary, the body sexual dimorphism is high. There were practically no associations between facial and body measures. These findings are interpreted in the light of trade-offs between environmental, cultural, and sexual selection pressures.

Keywords: Sexual dimorphism, Facial geometric morphometrics, fWHR, Body height, Facial dimorphism, Body dimorphism, Sex differences, Maasai

\section{Background}

The idea that human facial and body sexual dimorphism are both products of sexual selection has a long history (at least 150 years), dating back to Darwin's seminal book "The Descent of Man, and Selection in Relation to Sex" [1]. Since then, evolutionary biologists have been trying to detect which factors determine the strength of mate choice and intensity of sexual selection in each sex, and the progress made in this direction is really impressive

\footnotetext{
*Correspondence: marina.butovskaya@gmail.com

${ }^{3}$ Russian State University for the Humanities, Moscow 125047, Russia

Full list of author information is available at the end of the article
}

[2-7]. Sexual dimorphism has been interpreted as a product of the exposure to sex hormones (testosterone, estrogens) [8-17], and currently some studies pointed to sex differences in genes expression in human tissues [18] and sex differences in immune responses to pathogens, including COVID-19 [19]. Masculinity in males and femininity in females have been viewed as true signals of immune qualities, providing better prospects for survival and reproduction [20-23], and at least some aspects of immune function during early adolescence may positively predict sexually dimorphic 3D face shape in both men and women [24]. The role of ecological $[25,26]$ and cultural factors, particularly, norms, traditions, economy original author(s) and the source, provide a link to the Creative Commons licence, and indicate if changes were made. The images or other third party material in this article are included in the article's Creative Commons licence, unless indicated otherwise in a credit line to the material. If material is not included in the article's Creative Commons licence and your intended use is not permitted by statutory regulation or exceeds the permitted use, you will need to obtain permission directly from the copyright holder. To view a copy of this licence, visit http://creativecommons.org/licenses/by/4.0/. The Creative Commons Public Domain Dedication waiver (http://creativeco mmons.org/publicdomain/zero/1.0/) applies to the data made available in this article, unless otherwise stated in a credit line to the data. 
$[27,28]$ in the emergency of population variations in facial and body sexual dimorphism in humans has been also an object of intensive discussions [3, 8, 29]. Cranial (facial) form and robusticity demonstrate substantial variation related to climate and ecology (geography) [30], and sexual dimorphism varies between races and ethnics [31-38].

Male facial, as well as body masculinity has been frequently viewed as cues to good health and "good genes" (i.e., genes promoting health) [39], as producing and metabolizing testosterone is costly (and might lead to higher oxidative stress) [40]. Some studies, indeed, demonstrate that high testosterone levels increase muscularity and body weight [41], as well as positively associated with facial masculinity $[42,43]$. Studies conducted on Caucasian samples revealed certain relationships between facial and body traits. Face growth occurs in concordance with body growth [44], and according to allometry effects, facial shape is expected to be associated with body size $[45,46]$. In modern western populations, for example, in Germans, taller men were reported to have longer, narrower jaws and wider/fuller lips, besides, changes in male facial shape were more strongly associated with physical strength, which in turn was related to perceived masculinity [45]. However, today, it is known that relation between facial shape and body size is far more complicated and subjected to large population variation [38].

Masculine men report less interest in child rearing and higher rates of short-term relationships [47, 48]. It is hypothesized that women select masculine male partners when the costs of reduced paternal investment are compensated by some genetic benefits to future offspring [49]. Some studies suggest that short-term relationships may be beneficial in populations with high pathogen pressure [50,51]. Mating or reproductive success may be associated with development of such sexually dimorphic traits as muscularity, height, and facial and vocal masculinity [52]. Physical strength is an influential trait in male-male contest competition [53]. Some authors provided evidence for a stronger influence of male-male competition in modern western society. Based on data from young age cohort (18 to 34 years), it was demonstrated that more physically dominant men reported about higher mating success compared to more sexually attractive men [54]. Body size and androgen-dependent traits are of great importance for intra-sexual competition as well [55]. It may be asked in this context whether masculinity in males has being even more strongly positively selected in polygynous populations with high natural fertility profile, such as Maasai, Datoga, Ariaal, Turkana, or other East African pastoralists, since intrasexual competition between males in these populations has been really high. In relation to our study, it makes sense to note that Maasai, as Nilotic people of East Africa, are rather tall and skinny. The level of testosterone in men from such populations is usually lower, compared to men of Caucasian origin from western populations [56]. On the other hand, testosterone level does not differ much in different age groups, in contrast to men from western populations $[57,58]$, and their reproduction life extends to $70^{\text {th }}$ year and even further.

Physical height has a well-documented impact on human social status in western societies. Taller men in western societies have been perceived as stronger, smarter, and more dominant [59]. They are also known to have higher reproductive success [60], although the curvilinear effect on reproductive success in men should be taken into consideration [61]. Height may influence mate choice, particularly, "man taller than women" norm is widely followed both by men and women [62]. However, it is important to mention that this norm is far from being universal [63-65].

One of the facial parameters, which has attracted a special attention of anthropologists and behavioral scientists today, is the facial width-to-height ratio (fWHR), defined as the ratio of the bizygomatic width to the so-called upper facial height (measured from Nasion to Prosthion, or their soft-tissue approximations) [33, 66]. This index associates with facial masculinity and has been viewed as sexually dimorphic, being higher in males than females [33, 67-72]. Weston and colleagues [73] speculated that sexual dimorphism in the fWHR evolved via female choice as an attractive trait. However, a number of studies do not find any differences in FWHR between men and women [74-79], or report even higher fWHR in women compared to men [37].

It has been hypothesized that the fWHR is part of an evolved cueing system of intra-sexual threat and dominance in men [80]. Numerous studies connect the fWHR with dominance, threat, fighting $[66,81-86]$ (however, see: [87]), reproductive success [88, 89], and deception [90]. It was also hypothesized that fWHR was subjected to positive sexual selection in the whole genus Homo [91], and generally in higher primates [73]. fWHR may serve as honest cue to males' ability to cooperate in intergroup conflicts, hence selected as such indicator in intrasexual selection [92]. Particularly, it was demonstrated by Stirrat and Perrett [93] that fWHR in men associates with increase in cooperation with other in-group members during intergroup competition. Men with wider faces were more self-sacrificing and helpful to their group, while competing rivalry group. These findings make sense in the light of parochial altruism hypothesis [94-96]. 
However, the association between fWHR and behavioral traits may be much more complex, ecological, social, developmental factors should be considered, and the evolutionary hypothesis related to fWHR selection in humans and apes must be taken with caution. Wilson with co-authors reported the absence of sexual dimorphism on fWHR in chimpanzees, as well as no association between fWHR and dominance in this species [97], several studies failed to establish association between fWHR with aggression and dominance in men [98-101]. No associations between testosterone and fWHR [102105], and between the androgen receptor gene polymorphism and fWHR [103] in men were demonstrated.

In accordance with "good genes" hypothesis, significant positive association between major histocompatibility complex (MHC) heterozygosity (an indirect measure of improved immunity) and facial attractiveness has been reported in young British and Australian men [106, 107], but not women [107, 108]. Significant positive correlations between immune response (cytokine response before and after immune stimulation), attractiveness, and health were also found in African men [109]. However, some studies have failed to find a relationship between attractiveness and health $[110,111]$. Contradictive results may be due to variations in immunity parameters. The data on various parameters of immunity in relation to differences in androgen levels in men from well-nourished Western society, presented by Nowak with co-authors [112], suggest that androgens may act as immunomodulators rather than immunosuppressants. The immuneandrogen interaction may be highly affected by a number of physiological or ecological factors [112], including the availability of nutritional resources, the intensity pathogen exposure, the extrinsic mortality risk [113], various stresses [108], and living conditions [114].

Sexual dimorphism can be studied on the basis of various parameters: musculature, facial shape, body height, etc. Below, these variables and their relationships will be presented.

In this paper, we address the questions of universality of facial sexual dimorphism in modern humans (Homo sapiens), and its' association with body sexual dimorphism. For these purposes we investigate sex differences in full facial shape and linear facial measures in association with body sexual dimorphism in Maasai, the traditional seminomadic East African Nilotic population of Northern Tanzania. The Maasai population of Ngorongoro Conservation Area was selected because they remained highly traditional in their economy (pastoralists), ecology (semi-nomadic, with traditional way of living and exposed to regular threat from wild animals, including regular attacks of lions, hyenas, and other carnivorous on cattle and people), and culture (preserving the age-set system, clan organization, practicing polygyny, and high fertility).

\section{Methods}

\section{Study population}

The Maasai are the Maa-speaking pastoral people of Tanzania. According to a census conducted in 2007, their population in the Ngorongoro Conservation Area (NCA) was 70,000 [115]. The Maasai culture and social structures are highly conservative [116]. Maasai society is structured around two major social institutions: the age-set system and the clans [117]. Today, the Maasai of the NCA are exclusively pastoralists, as far as any sort of agricultural activity is not allowed inside the habitat [118]. Currently, about half of the married men are in polygynous relationships with an average of 2.8 wives per man [119]. A system of territorial groups (sections), clans, and age-sets provide the basis of social and economic cooperation.

The age-set system remained to be important in men's life. Adjacent age-sets are in lifelong political and ritual opposition and competition. Every 15 years, a new ageset is opened. All boys of suitable age become circumcised during this period and join a group of "ilmurran" ("junior warriors"). Murrans spend time traveling, herding, and feasting in the bush. They also act as warriors, defend local households from raids of neighboring tribes (Datoga and Sukuma), and in turn steal cattle from them [118]. Those who are more successful in these activities gain higher social prestige, and this may facilitate access to female mating partners. Around the 30-35 years of age men enter the stage of junior elders, and according to traditional norms men are allowed to marry [117]. Currently, however, men started to marry earlier; however, they still follow a number of restrictions, particularly do not take food with their wives until they officially join the junior elders stage. Since this time physical strength and competition do no longer of primary importance, and men gradually gaining social respect and power. Fifteen years later, they become senior elders, and gain significant authority over decisions regarding resource use, livestock, water resources, mutual aid, and other issues [120].

\section{Study sample}

Our data were collected in 2016 in and around Endulen village, located in NCA. All Maasai who participated in this study were living in traditional Maasai households, practicing pastoralism and traditional cultural norms. The total sample size was 305 individuals (185 men and 120 women) with an age range between 17 and 90 years [121]. 
The study was conducted according to the principles of the Declaration of Helsinki. The population studied was illiterate and therefore a written consent could not be obtained. The participants gave verbal consents and were told that their participation was voluntary and that they could withdraw from the study at any time. The study protocol and consent procedure received ethical approval from the Ethics Committee of Moscow State University; research permit was obtained from the Tanzania Commission for Science and Technology (COSTECH) and administration of Ngorongoro Conservation Area (NCA).

The data that support the findings of this study are available from the corresponding author upon reasonable request.

\section{Facial photographs}

Each participant was photographed in full-face perspective. Subjects were seated at $1.80 \mathrm{~m}$ distance to the camera and were instructed to look straight into the lens (Nikon D90, $70 \mathrm{~mm}$ lens equivalent to $105 \mathrm{~mm}$ for 35 $\mathrm{mm}$ film) while maintaining a neutral facial expression. A scale bar (in $\mathrm{cm}$ ) was included in each image. Faces were positioned visually according to the Frankfort Horizontal Plane (FH) with the lens at eye height.

\section{Geometric morphometrics}

Facial shape analysis was held using geometric morphometrics [122]. Seventy-one facial landmarks and semilandmarks were manually placed on each photograph using tpsDig2 2.17 [123]. Landmarks' positions were set based on the configuration developed by Windhager et al. [45], which has been already used in our earlier studies [37, 121, 124]. This configuration included 37 landmarks, which are known to be classical anthropometrical approximations to cranio-facial and soft-tissue facial shape determinants $[33,45,66,125,126]$ as well as 34 semilandmarks, used for covering facial outline, eyebrows and lips shapes.

To ensure reliability of the landmarks' digitalization, two independent observers were invited to place all 71 landmarks and semilandmarks on 40 randomly selected photographs (20 male and 20 female faces). The repeatability of landmarks' digitalization was assessed by means of geometric morphometrics as the ratio of among-individual variance component to the sum of among-individual and measurement error components [127], using "vegan" package for R (adonis() function with Euclidian method) [128]. The inter-observer agreement was 0.91 . We considered the method reliable enough to proceed with manual digitalization of landmarks by one of the observers.
Facial centroid size as one of the major measures of allometry $[46,127]$ was calculated using «shapes» package for $\mathrm{R}$ [129] after scaling all facial configurations to centimeters.

All facial configurations were standardized for the position, orientation, and scale by Generalized Procrustes superimposition together with sliding semilandmarks using minimum bending energy criterion in "geomorph" package for R [130].

Since facial asymmetry estimation was not among the goals of the present study, all facial configurations were symmetrized [131] in order to reduce possible distortion due to head positioning in the $2 \mathrm{D}$ projection. Symmetrization was performed in R [132], using basic functions, and those developed by Claude [133].

Association of the facial shape with sex, age, and body mass index (BMI) were tested by multivariate analysis of variance using "vegan" package for R (adonis() function with Euclidian method) [128].

Visualization of the results of morphometric analysis was realized using different methods. Thin-plate deformation grids with pairwise comparison of target configurations were made in $\mathrm{R}$ using functions developed by Claude [133], and adjusted by authors according to the purposes of the present study. Geometric morphometric morphs were visualized by unwarping and averaging photographs in tpsSuper 2.04 [45, 123].

\section{Classical facial metrics}

Classical facial indices, which are known to demonstrate certain degree of sexual dimorphism in humans, were calculated based on coordinates of facial landmarks after Procrustes superimposition. These indices included upper width-to-height ratio (upper fWHR); total widthto-height ratio (total fWHR); lower width-to-height ratio (lower fWHR); cheekbone prominence; and mandibular and nasal indices, mouth shape, mouth-face index, and height-to-width ratio of the eye [37, 66, 72]. The locations of the landmarks used for calculation of these indices are presented in Fig. 1. Details on the estimated facial parameters and definitions can be found in Table 1 of the "Results" section.

\section{Anthropometric measurements}

Body sexual dimorphism in humans can be studied by a number of parameters that reflect the development of bones, muscles, and adipose tissues. Parameters targeting skeletal development are usually measured in lowfat parts of the human body (e.g., under-chest diameter, wrist and ankle diameters, body height). Muscular development can be assessed by handgrip strength, upper arm, calf, and thigh circumferences, as well as by body mass index (BMI); however, the latter four parameters also 


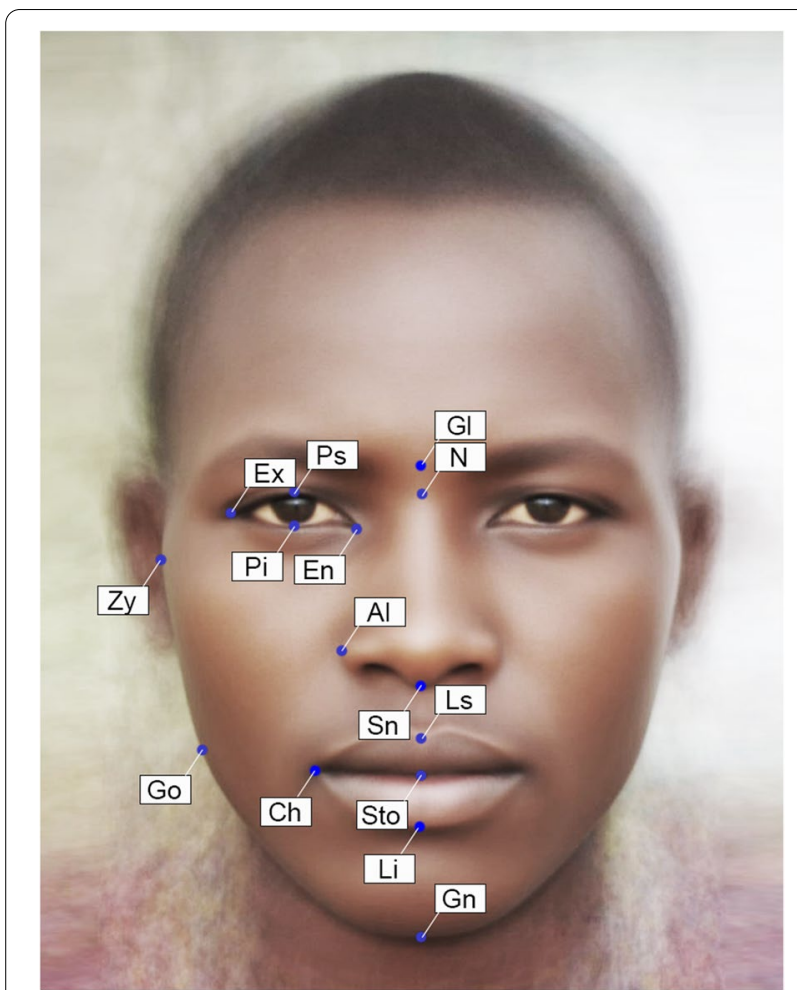

Fig. 1 Facial landmarks used in the classical facial metrics. Averaged Maasai portrait. Single landmarks: Gl—glabella (midpoint between the center points of the lower eyebrows' hairlines); $\mathrm{N}$-nasion

(midpoint between the highest points of the eyelids); $\mathrm{Sn}$ - subnasale (the midpoint of the base of the columella); Ls-labiale superius (the outermost point on the upper lip vermillion in the midsagittal plane); Sto-stomion (the point in the midsagittal plane where upper and lower lips vermillions meet); Li-labiale inferius (the outermost point on the lower lip vermillion in the midsagittal plane); Gn—gnathion (the lowest point of the chin in the midsagittal plane). Paired landmarks: Zy —zygion (the most lateral point of the zygomatic arch); Go-gonion (the most inferior and lateral point on the external angle of the mandible); Ch-cheilion (the outer corner of the mouth); $\mathrm{Al}$ - alare (the most lateral point of the nasal wing); Ex-exocanthion (the lateral point of the eye fissure); En-endocanthion (the medial of the eye fissure); Ps - palpebrale superius (the highest point of the free margin of the upper eyelid); $\mathrm{Pi}$ - palpebrale inferius (the lowest point of the free margin of the lower eyelid)

account for deposition of fat. In turn, the development of adipose tissues can be measured by various body skinfolds and hips circumference. Combination of different parameters provides more accurate estimates of certain developmental processes.

The data on body height $(\mathrm{cm})$, weight $(\mathrm{kg})$, wrist diameter of the right hand $(\mathrm{cm})$, handgrip strength $(\mathrm{kg})$, triceps skinfold of the right hand $(\mathrm{cm})$, upper arm circumference of the right hand $(\mathrm{cm})$, under-chest, and hips circumferences $(\mathrm{cm})$ were collected. The body height was measured with anthropometer (GPM Swiss made) with an accuracy of $\pm 0.1 \mathrm{~cm}$. Body weight (mass) was measured by electronic scales (SECA, Germany) accurate to 0.1 $\mathrm{kg}$. BMI was calculated, using bodyweight in kilograms divided by height in meters squared $\left(\mathrm{kg} / \mathrm{m}^{2}\right)$. Circumferences were measured by tape with the accuracy of $0.1 \mathrm{~cm}$. Wrist diameter of the right hand was measured by sliding caliper (Martin type, M-222) with the accuracy of 1 $\mathrm{mm}$. Handgrip strength (HGS) was assessed with a portable hand dynamometer (DMER-120, Tulinovsky Instruments, Russia). Participants were instructed to press the dynamometer as hard as they could, in standing position, and with the arm stretched downwards. Right HGS was measured twice and the highest value of the measurements was used in the statistical analyses. Triceps skinfold was measured with baseline skinfold caliper (model 12-110, Lafayette Instrument Company).

\section{Statistical analysis for classical facial and body measurements}

All classical morphological parameters were normally distributed according to Kolmogorov-Smirnov test. Sex differences in BMI were assessed using Student's $t$ test. Sexual dimorphism in classical facial indices was assessed with control for BMI, since this parameter contributed considerably to facial shape variation. For this purpose, analysis of covariance (ANCOVA) was used, where each facial index was set as dependent variable, and BMI and sex, as predictors. To assess the effect size for sex, partial $\mathrm{Eta}^{2}$ was used, as it partializes out the effect of other independent variables (in case of multiple predictors), which allows estimating the effect size for each predictor specifically. The associations between facial indices of Maasai men and women with facial centroid size, and body height (as well as a number of other body parameters) were also tested with control for BMI using multivariate analysis of covariance (MANCOVA), where a number of selected traits were set as dependent variables and BMI and a trait of interest (facial centroid size, body height, or any of the other body parameters) served as predictors. The measure of the effect size in these cases was also partial $\mathrm{Eta}^{2}$ for the predictor of interest. Association between body height and facial centroid size for men and women was tested using linear regression analysis. For estimating sex differences in body parameters, Student's $t$ test was used. In case of testing subsamples (different age cohorts), the Student's test was performed with control for equivalence of variances (Levene's test). Hedges' g was reported as an effect size for unequal sample sizes. To estimate which body parameters were the main predictors of sex in Maasai, binary logistic regression with stepwise inclusion of predictors (forward Wald algorithm) was used, where sex was set as a dependent 
Table 1 Sex differences in facial traits of young- and mid-adult Maasai controlled for BMI

\begin{tabular}{|c|c|c|c|c|c|c|c|c|c|}
\hline \multirow[t]{2}{*}{ Age } & \multirow[t]{2}{*}{ Facial trait } & \multirow[t]{2}{*}{ Definition } & \multicolumn{2}{|l|}{ Men } & \multicolumn{2}{|c|}{ Women } & \multirow[t]{2}{*}{$F$} & \multirow[t]{2}{*}{ Partial Eta ${ }^{2}$} & \multirow[t]{2}{*}{ Sig. } \\
\hline & & & $M$ & $S D$ & $M$ & $S D$ & & & \\
\hline \multirow[t]{12}{*}{ Young-adults (17-29 years) } & \multirow[t]{4}{*}{ Upper fWHR } & $|Z y-Z y| /|N-S t o|$ & 1.85 & 0.12 & 1.85 & 0.11 & 0.01 & $<0.001$ & 0.955 \\
\hline & & $|Z y-Z y| /|G l-S t o|$ & 1.68 & 0.12 & 1.67 & 0.09 & 0.41 & 0.004 & 0.525 \\
\hline & & $|Z y-Z y| /|N-L s|$ & 2.15 & 0.18 & 2.15 & 0.14 & 0.01 & $<0.001$ & 0.920 \\
\hline & & $|Z y-Z y| /|G|-L s \mid$ & 1.93 & 0.17 & 1.91 & 0.12 & 0.53 & 0.005 & 0.470 \\
\hline & Total fWHR & $|Z y-Z y| /|N-G n|$ & 1.16 & 0.07 & 1.18 & 0.06 & 1.30 & 0.012 & 0.257 \\
\hline & Lower fWHR & $|Z y-Z y| /|S n-G n|$ & 2.05 & 0.18 & 2.09 & 0.16 & 1.78 & 0.016 & 0.185 \\
\hline & Cheekbone prominence & $|Z y-Z y| /|G o-G o|$ & 1.25 & 0.06 & 1.24 & 0.05 & 0.01 & $<0.001$ & 0.960 \\
\hline & Mandibular index & $\mid$ Go-Go| / |Sto-Gn| & 2.55 & 0.23 & 2.63 & 0.25 & 3.34 & 0.030 & $0.070^{+}$ \\
\hline & Nasal index & $|\mathrm{Al}-\mathrm{A}||/| \mathrm{N}-\mathrm{Sn} \mid$ & 0.86 & 0.09 & 0.81 & 0.06 & 9.09 & 0.078 & $0.003^{*}$ \\
\hline & Mouth shape & $|\mathrm{Ls}-\mathrm{Li}| /|\mathrm{Ch}-\mathrm{Ch}|$ & 0.45 & 0.08 & 0.45 & 0.06 & 0.01 & $<0.001$ & 0.931 \\
\hline & Mouth-face index & $|C h-C h| /|Z y-Z y|$ & 0.39 & 0.03 & 0.38 & 0.03 & 4.43 & 0.038 & $0.039 *$ \\
\hline & Height-to-width ratio of the eye (mean) & $|\mathrm{Ps}-\mathrm{Pi}| /|\mathrm{Ex}-\mathrm{En}|$ & 0.27 & 0.04 & 0.28 & 0.05 & 1.65 & 0.015 & 0.202 \\
\hline \multirow[t]{12}{*}{ Mid-adults ( $30-50$ years) } & \multirow[t]{4}{*}{ Upper fWHR } & $|Z y-Z y| /|N-S t o|$ & 1.78 & 0.11 & 1.81 & 0.11 & 0.60 & 0.006 & 0.441 \\
\hline & & $|Z y-Z y| /|G l-S t o|$ & 1.63 & 0.12 & 1.64 & 0.11 & 0.12 & 0.001 & 0.732 \\
\hline & & $|Z y-Z y| /|N-L s|$ & 2.02 & 0.14 & 2.07 & 0.15 & 1.71 & 0.016 & 0.194 \\
\hline & & $|Z y-Z y| /|G|-L s \mid$ & 1.83 & 0.14 & 1.84 & 0.14 & 0.01 & $<0.001$ & 0.905 \\
\hline & Total fWHR & $|Z y-Z y| /|N-G n|$ & 1.15 & 0.06 & 1.16 & 0.06 & 0.78 & 0.007 & 0.378 \\
\hline & Lower fWHR & $|Z y-Z y| /|S n-G n|$ & 2.08 & 0.19 & 2.09 & 0.20 & 0.01 & $<0.001$ & 0.926 \\
\hline & Cheekbone prominence & $|Z y-Z y| /|G o-G o|$ & 1.24 & 0.05 & 1.22 & 0.05 & 1.61 & 0.015 & 0.208 \\
\hline & Mandibular index & $\mid$ Go-Go| / |Sto-Gn| & 2.62 & 0.30 & 2.69 & 0.31 & 0.77 & 0.007 & 0.381 \\
\hline & Nasal index & $|\mathrm{Al}-\mathrm{A} \| / / \mathrm{N}-\mathrm{Sn}|$ & 0.83 & 0.09 & 0.81 & 0.07 & 3.82 & 0.034 & $0.053^{+}$ \\
\hline & Mouth shape & |Ls-Li|/|Ch-Ch| & 0.39 & 0.07 & 0.41 & 0.08 & 2.13 & 0.019 & 0.148 \\
\hline & Mouth-face index & $|C h-C h| /|Z y-Z y|$ & 0.40 & 0.03 & 0.39 & 0.03 & 0.68 & 0.006 & 0.412 \\
\hline & Height-to-width ratio of the eye (mean) & $|\mathrm{Ps}-\mathrm{Pi}| /|\mathrm{Ex}-\mathrm{En}|$ & 0.27 & 0.06 & 0.25 & 0.04 & 2.71 & 0.025 & 0.103 \\
\hline
\end{tabular}

ANCOVA results are presented. Dependent variable: facial trait; independent variables: 1) BMI, 2) sex. Effect size (partial Eta ${ }^{2}$ ) and significance level ( $p$ ) are presented only for sex (after controlling for BMI). Definitions of the facial landmarks used for facial traits calculation can be found in Fig. 1. Significant sex differences (*) and statistical trends $\left({ }^{+}\right)$are presented in bold

variable. To test associations between handgrip strength and body parameters, linear regression (stepwise forward algorithm) was used. Statistical analysis was performed using SPSS version 23.0 (IBM Corp., Armonk, NY, USA). The significance level was set at 0.05 .

\section{Results}

\section{Sexual dimorphism of Maasai facial shape}

The degree of sex differences in facial shapes of Maasai were first tested on the general sample including subjects of all ages. Since the age range was very wide $\left(\mathrm{age}_{\min }=\right.$ 17 ; age $_{\max }=90$ ), we expected quite noticeable contribution of this factor into the facial shape specificity. Therefore, possible age effects were first eliminated by multivariate analysis of variance where age was set as the first of the two independent variables. According to this linear model, sex (controlled for age) explained only 1.8\% of the total variance of the facial shape of Maasai $(p<$ $0.001)$. At the same time, $6 \%$ of the total variance in shape was explained by age $(p<0.001)$.
Considering very wide age range, there could be some nonlinear associations, since ontogenetic development is not a uniform process, and the intensity and direction of morphogenesis may differ at different stages of individual development. To estimate possible nonlinear effects, we have divided the general sample into three subsamples corresponding to the three age cohorts (young-adults: $17-29$ years; mid-adults: $30-50$ years; elderly $>50$ years). The age thresholds per each cohort were chosen based on the specific features of Maasai social structure (see "Methods" section). This classification has already been implemented in our earlier study of this population [121]. The distribution of subjects across three age cohorts is presented in Fig. 2.

According to the results, Maasai women demonstrated more pronounced age-related changes in facial shape during young-adult period of life, compared to Maasai men. At the same time, facial shape of Maasai men changed more gradually (Fig. 3a). Generally, sex differences in facial morphology were very weak in the youngest age cohort (17-29 years), but increased with age and 


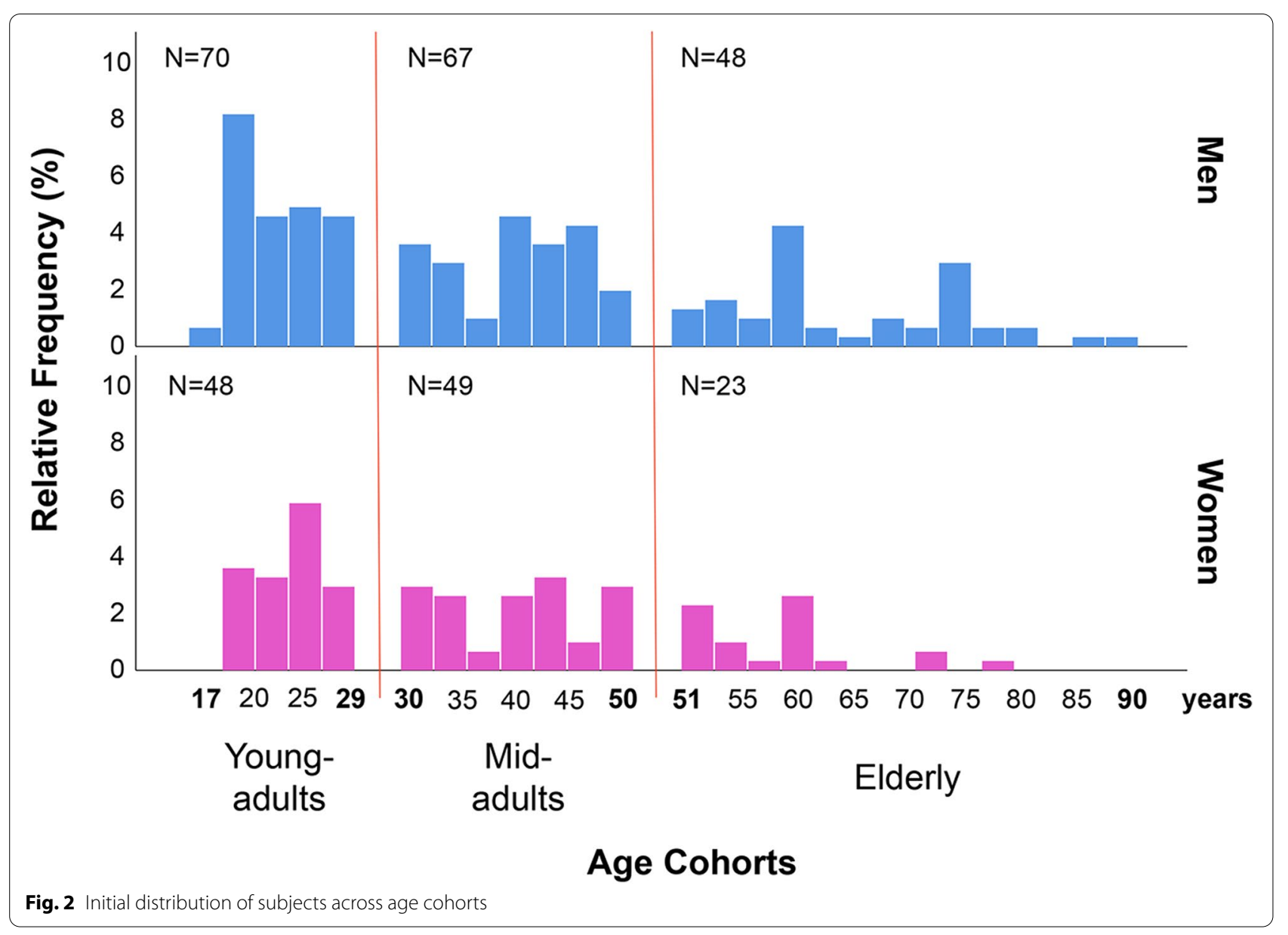

\begin{tabular}{|c|c|c|c|c|c|}
\hline \multicolumn{6}{|c|}{ Facial shape } \\
\hline \multirow{3}{*}{ Age } & & $17-29$ years & $30-50$ years & $51-65$ years & \multirow[b]{2}{*}{$\mathbf{R}^{2}$} \\
\hline & Men & * & & & \\
\hline & Women & * & & & 0.05 \\
\hline Sex & & * & ** & & 0.04 \\
\hline BMI & & ** & ** & & 0.03 \\
\hline $\operatorname{Sex}(c$ & ont. BMI) & * & * & & 0.02 \\
\hline
\end{tabular}

were most significant in mid-adults (30-50 years), where sex explained around $3 \%$ of variance in facial shape. By the elderly period, sex differences reached the level of $4 \%$ of explained variance; however, in the elderly years, differences were not statistically significant (Fig. 3b).

Next, we have tested the impact of BMI on the facial shape in each of the age cohorts. Sex differences in BMI 
were significant for young-adults (mean $\mathrm{BMI}_{\text {women }}=$ $21.0 \pm 3.8$; mean $\mathrm{BMI}_{\text {men }}=19.8 \pm 2.2$; Student's $t$ test: $N=111 ; t=-2.161 ; p=0.033$ ), and mid-adults (mean $\mathrm{BMI}_{\text {women }}=21.7 \pm 3.5$; mean $\mathrm{BMI}_{\text {men }}=19.8 \pm 2.3$; Student's $t$ test: $N=110 ; t=-3.293 ; p=0.001$ ), with women having higher BMI than men, which was especially pronounced in mid-adult cohort. The BMI was significantly associated with facial shape both in youngand mid-adult Maasai. Results of the analysis revealed that increase in sexual dimorphism in facial shape within the mid-adult cohort was at least partially caused by the BMI differences between men and women, since after controlling for BMI (by adding this parameter as the first of the two independent variables in the multivariate analysis of variance), sexual dimorphism in Maasai facial shape within the mid-adult cohort decreased (Fig. 3c). The latter indicates that within the whole age range of $17-50$ years, sex explains about $2 \%$ of the total variance of the facial shape of Maasai. When young-adults and mid-adults samples were compared, it was founds that in age cohort between 30 and 50 years, differences in BMI between men and women added to increase of sexual dimorphism in facial shape. This is well illustrated by the visualization of the sex differences in facial shape for each age cohort presented in Fig. 4 (the thin-plate grid was deformed from the reference shape (female, in red) toward the male shape (in blue); for enhancing the details, the differences were exaggerated by a factor of 3 ).

The visualizations presented in Fig. 4 support statistical results. In the youngest age cohort, sex differences in facial shape were very small-even after 3-fold exaggeration, male and female mean configurations almost coincided. However, even here the tendency for narrower and more prolonged in vertical plane male faces is recognizable. Among young-adults, men also had slightly wider noses and narrower-set and lower eyebrows, as well as higher forehead hairline. Generally, this tendency reached its' peak in mid-adult cohort, when female faces were relatively wider, especially in the area of bigonial width, and female nasal shape reflected generally smaller noses in both width and height directions. However, wider female faces compared to males', partly represent higher female BMI, which may result in increased fat deposition in the cheeks area. In the elderly age cohort, the general degradation of the lower lip vermillion is observed in males, as well as further narrowing of the lower face and vanishing of the sex-specific male morphology in the eyebrows and nasal regions of the face. At the same time, female facial traits within the elderly cohort changed less dramatically compared to younger

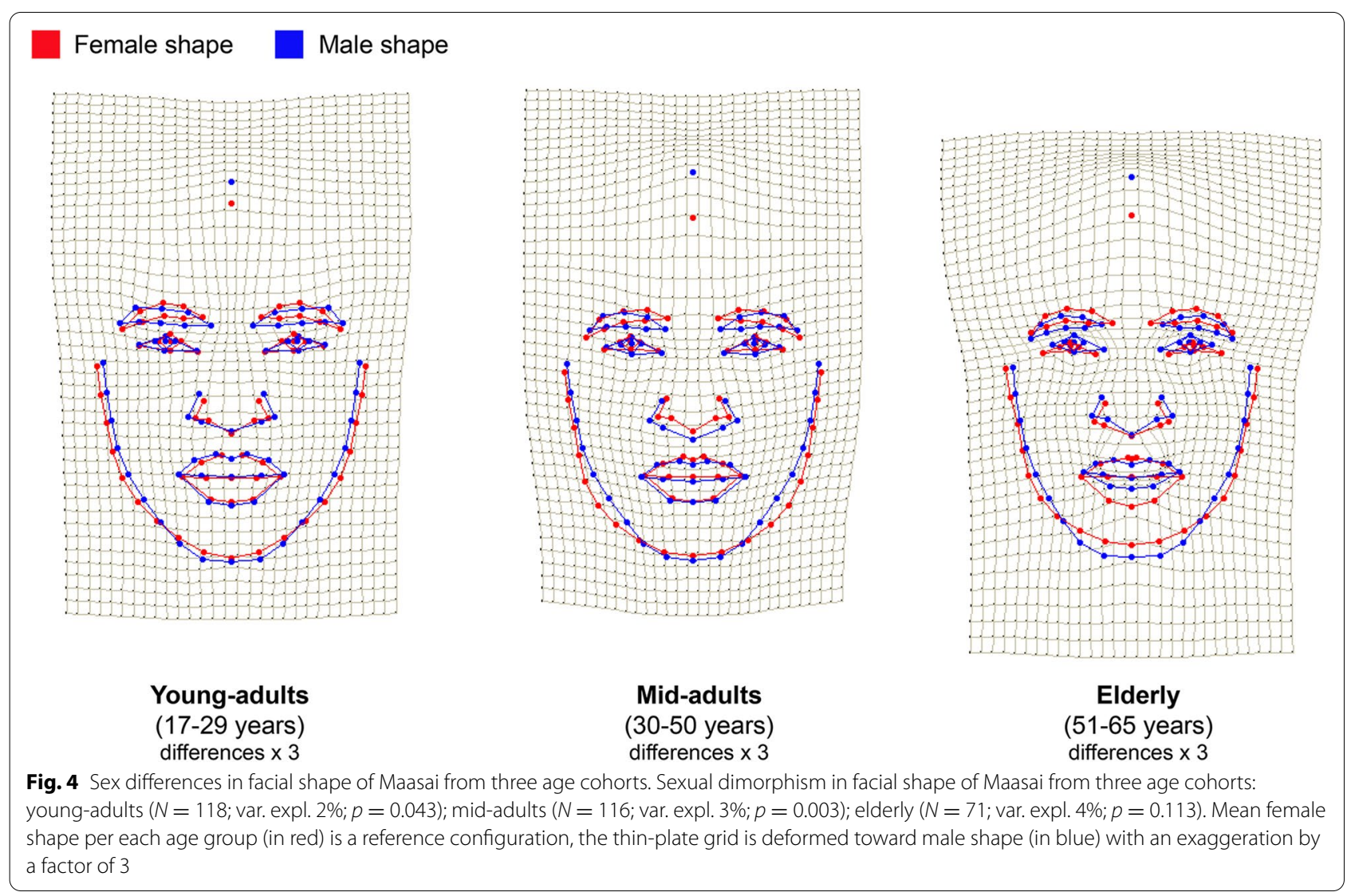


ages, which may suggest that aging processes affected male facial morphology to a greater extent.

For clarity, Fig. 5 represents facial shape differences between Maasai men and women as averaged individual portraits unwarped upon target configurations across three age cohorts.

\section{Sexual dimorphism in facial indices of adult Maasai}

Despite the fact that some significant sex differences in Maasai facial shapes could be visualized after 3-fold exaggeration, generally, male and female Maasai faces were very similar. Analysis of sex differences in a number of facial indices, which are usually considered sexually dimorphic, are presented in Table 1 . Analysis (with control for BMI) was performed only for young- and mid-adults, since only in these age cohorts significant sex differences in facial shape were revealed by geometric morphometrics. Upper facial width-to-height ratio (fWHR) was calculated in all four known variants, measured both from the eyebrows (glabella, Gl) and upper eyelids (nasion, N) to the upper lip line (labiale superius, Ls) and the line between upper and lower lips vermillions (stomion, Sto) [37]. Since lip vermillions in Maasai are very thick, as well as in most of African and some other

(a) Young-adults (17-29 years)

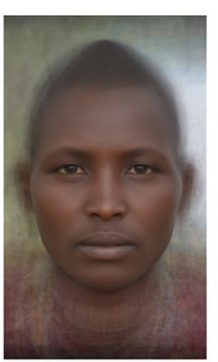

female $\times 3$

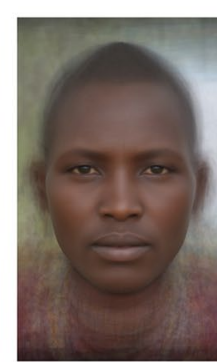

female

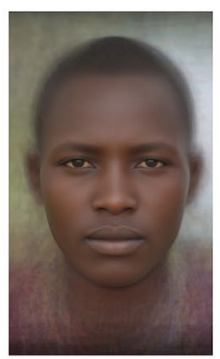

indifferent

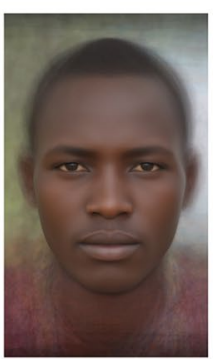

male

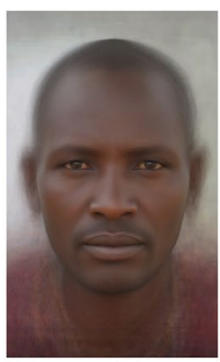

male

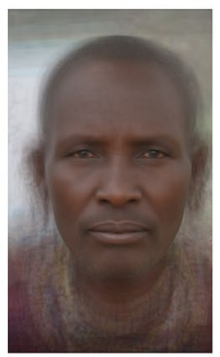

male

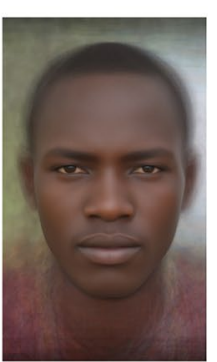

male $\times 3$

(b) Mid-adults (30-50 years)

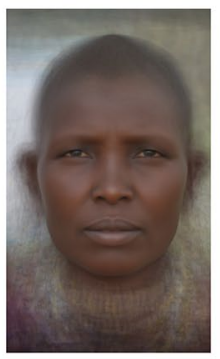

female $\times 3$

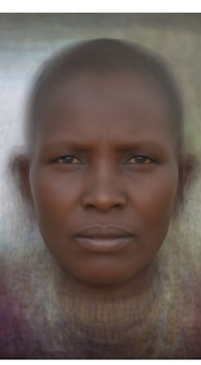

female

(c) Elderly (51-65 years)

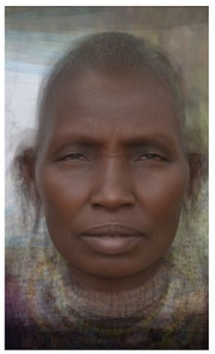

female $\times 3$

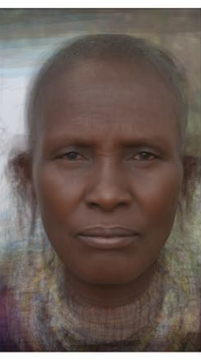

female

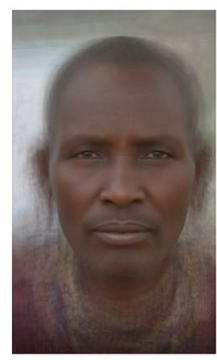

indifferent

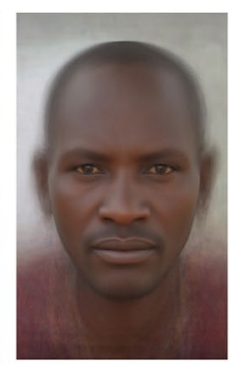

male $\times 3$

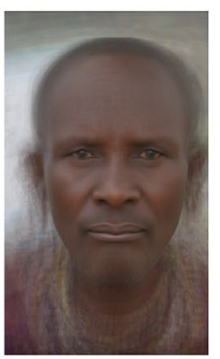

male $\times 3$

Fig. 5 Averaged facial portraits representing differences between Maasai men and women. Sex differences in facial shape of Maasai from three age cohorts. Geometric morphometric morphs display the facial shape change from a sexually undifferentiated face (in the middle) toward the average female (to the left) and male (to the right) face. The outer configurations represent differences exaggerated by a factor of 3. Sex differences were significant for young-adults (var. expl. $=2 \%, p<0.05$ ), and for mid-adults (var. expl. $=3 \%, p<0.01$ ) (according to permutation test with 10000 permutations) 
populations, stomion approximation in this case is more informative [33, 37, 76].

As was expected based on geometric morphometrics, none of the variants of the upper fWHR was sexually dimorphic in Maasai; moreover, women on average had slightly higher values of this trait (although differences were not significant). The most sexually dimorphic regions of the face were the shape of the jaw (mandible index, marginally significant in young-adults), nose (nasal index in young-adults and marginally significant in midadults), and mouth (mouth-face index in young-adults) (Table 1).

\section{Sexual dimorphism in Maasai body parameters}

Mean values of tested body parameters and significance of sex differences are presented in Table 2.

With an exception of body weight in older age cohort, all body parameters were sexually dimorphic, with highest level of dimorphism (more than 1 SD) for body height, handgrip strength, and facial size both for young and mid-adults.

On the next step, we tested the distribution of the body traits' values across all ages for men and women. These distributions were best explained by nonlinear regression models. Some of the body parameters had generally higher values in men (body height, body weight, handgrip strength, under-chest circumference, wrist diameter, facial centroid size; Fig. 6), while others were more characteristic of women (higher body mass index, higher hips and upper arm circumferences, and larger triceps skinfold; Fig. 7). Male-specific parameters were more related to general body size, massiveness, and strength, while female-specific parameters were mostly related to increased body fat deposition, which is generally more typical for women than men.

Our cross-sectional data demonstrate that most of the body parameters had non-linear developmental trajectory in men and women during the lifespan (Figs. 6 and 7). Especially, this was the case for those parameters, which were initially better developed in women than in men (Fig. 7). Female BMI, hips circumference, and upper arm circumference along with triceps skinfold exceeded those of men in adulthood, but crucially decreased closer to elderly years of Maasai women. Taking into consideration such sex-specific nonlinear changes in body parameters of Maasai, only young- and mid-adult age cohorts were addressed for testing general sex differences in body parameters.

It can be already deduced from Figs. 6 and 7 which body measures are higher in Maasai men, and which in

Table 2 Sex differences in body parameters of young- and mid-adult Maasai

\begin{tabular}{|c|c|c|c|c|c|c|c|c|c|}
\hline \multirow[t]{2}{*}{ Age } & \multirow[t]{2}{*}{ Body parameter } & \multirow[t]{2}{*}{ Unit } & \multicolumn{2}{|l|}{ Men } & \multicolumn{2}{|c|}{ Women } & \multirow[t]{2}{*}{$t(\mathrm{df})$} & \multirow[t]{2}{*}{ Hedges' g } & \multirow[t]{2}{*}{ Sig. } \\
\hline & & & $M$ & $S D$ & $M$ & $S D$ & & & \\
\hline \multirow[t]{10}{*}{ Young-adults (17-29 years) } & Body height & $\mathrm{cm}$ & 167.5 & 7.1 & 155.3 & 5.4 & $10.02(115)$ & 1.88 & $<0.001$ \\
\hline & Body weight & $\mathrm{kg}$ & 55.6 & 8.5 & 50.7 & 9.5 & $2.87(110)$ & 0.55 & 0.005 \\
\hline & Body mass index (BMI) & $\mathrm{kg} / \mathrm{m}^{2}$ & 19.8 & 2.2 & 21.0 & 3.8 & $-2.16(109)$ & -0.41 & 0.033 \\
\hline & Handgrip strength & $\mathrm{kg}$ & 38.4 & 8.9 & 26.2 & 4.7 & $9.62(110)^{\mathrm{a}}$ & 1.63 & $<0.001$ \\
\hline & Wrist diameter & $\mathrm{mm}$ & 55.9 & 3.6 & 52.0 & 5.1 & $4.83(109)$ & 0.92 & $<0.001$ \\
\hline & Upper arm circumference & $\mathrm{cm}$ & 24.4 & 2.4 & 24.2 & 2.5 & $0.43(114)$ & - & 0.668 \\
\hline & Triceps skinfold & $\mathrm{mm}$ & 8.7 & 5.4 & 13.8 & 5.4 & $-4.97(115)$ & -0.94 & $<0.001$ \\
\hline & Under-chest circumference & $\mathrm{cm}$ & 77.5 & 4.7 & 72.8 & 4.9 & $5.32(115)$ & 0.98 & $<0.001$ \\
\hline & Hips circumference & $\mathrm{cm}$ & 87.4 & 6.3 & 90.6 & 5.7 & $-2.76(112)$ & -0.53 & 0.007 \\
\hline & Facial centroid size & $\mathrm{cm}$ & 56.0 & 3.8 & 51.6 & 3.4 & $6.35(116)$ & 1.20 & $<0.001$ \\
\hline \multirow[t]{10}{*}{ Mid-adults (30-50 years) } & Body height & $\mathrm{cm}$ & 168.1 & 6.4 & 156.3 & 6.1 & $9.89(114)$ & 1.88 & $<0.001$ \\
\hline & Body weight & $\mathrm{kg}$ & 56.1 & 8.7 & 53.1 & 9.1 & $1.81(108)$ & 0.33 & 0.073 \\
\hline & Body mass index (BMI) & $\mathrm{kg} / \mathrm{m}^{2}$ & 19.8 & 2.4 & 21.7 & 3.5 & $-3.14(79)^{\mathrm{a}}$ & -0.65 & 0.001 \\
\hline & Handgrip strength & $\mathrm{kg}$ & 37.9 & 7.9 & 25.9 & 5.4 & $9.14(112)$ & 1.72 & $<0.001$ \\
\hline & Wrist diameter & $\mathrm{mm}$ & 56.1 & 3.7 & 53.2 & 5.5 & $3.26(109)$ & 0.64 & 0.002 \\
\hline & Upper arm circumference & $\mathrm{cm}$ & 24.9 & 2.3 & 27.2 & 9.2 & $-1.90(74)^{a}$ & -0.37 & 0.087 \\
\hline & Triceps skinfold & $\mathrm{mm}$ & 9.0 & 8.3 & 16.6 & 7.5 & $-5.10(114)$ & -0.95 & $<0.001$ \\
\hline & Under-chest circumference & $\mathrm{cm}$ & 79.9 & 5.8 & 74.7 & 7.8 & $4.17(114)$ & 0.77 & $<0.001$ \\
\hline & Hips circumference & $\mathrm{cm}$ & 89.4 & 6.3 & 93.8 & 7.5 & $-3.38(112)$ & -0.65 & 0.001 \\
\hline & Facial centroid size & $\mathrm{cm}$ & 57.9 & 3.8 & 53.1 & 3.4 & $6.99(114)$ & 1.32 & $<0.001$ \\
\hline
\end{tabular}

Results of the Student's $t$ test with control for equivalence of variances (Levene's test) are presented; $d f$ - degrees of freedom

${ }^{a}$ Adjusted according to significant results of the Levene's test. Hedges' $g$ effect size for unequal sample sizes (negative when female values are larger than male) 


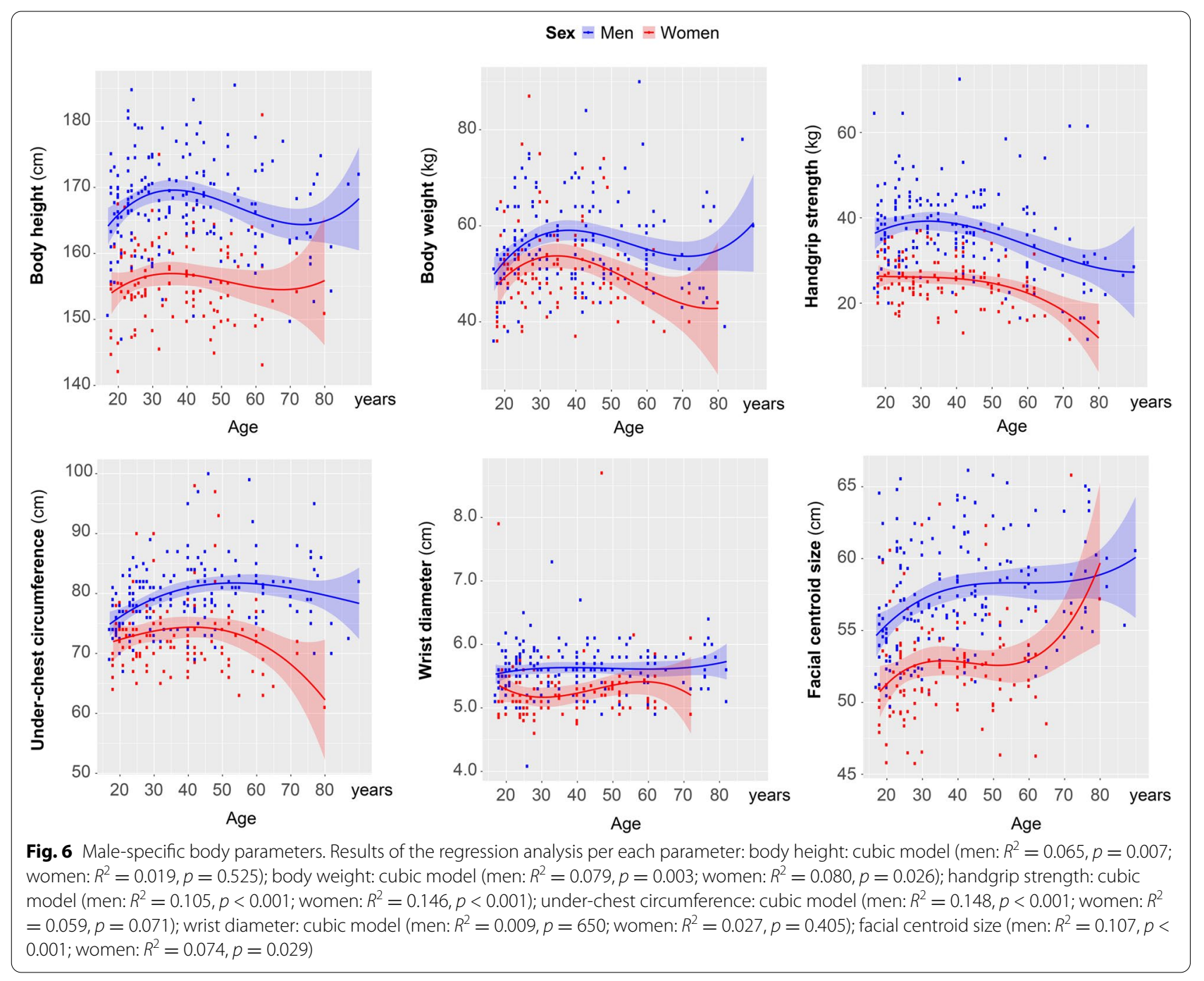

women. However, to see which body parameters contribute the most to the body sexual dimorphism, we have run stepwise binary logistic regression with forward Wald algorithm. The following independent variables were entered to the analysis: body height, body weight, handgrip strength, under-chest circumference, wrist diameter, facial centroid size, BMI, hips circumference, upper arm circumference, and triceps skinfold. Independent variables were added to the model stepwise starting from the first predictor with the most powerful predicting power. Each next variable is added on the consequent step improving the model until its quality drops. Those predictors, which do not add to the model capacity, were not included. Here, stepwise regression was terminated at the step 4 , and hence the model included 4 main predictors of sex (namely body height, under-chest and hips circumferences, and handgrip strength). The results of the regression are presented in Table 3. The model based on these four body parameters was able to predict Maasai sex with probability of $88 \%$.

\section{Facial parameters and allometry in Maasai}

To test for allometric effects on facial traits of young- and mid-adult Maasai, we have analyzed possible associations of the male and female facial shapes with body height, and facial centroid size (taken as natural logarithm of centroid size), as two main measures of static allometry in humans [46]. Since it was already demonstrated that faces of young (17-29 years) and mid-adult (30-50 years) Maasai had similar patterns of sexual variability, with BMI being the main distinguishing factor (Figs. 3 and 4), these two age cohorts were pooled for static allometry testing. The Procrustes superimposition with sliding semilandmarks, and subsequent symmetrization, were held separately for men and women from 17 to 50 

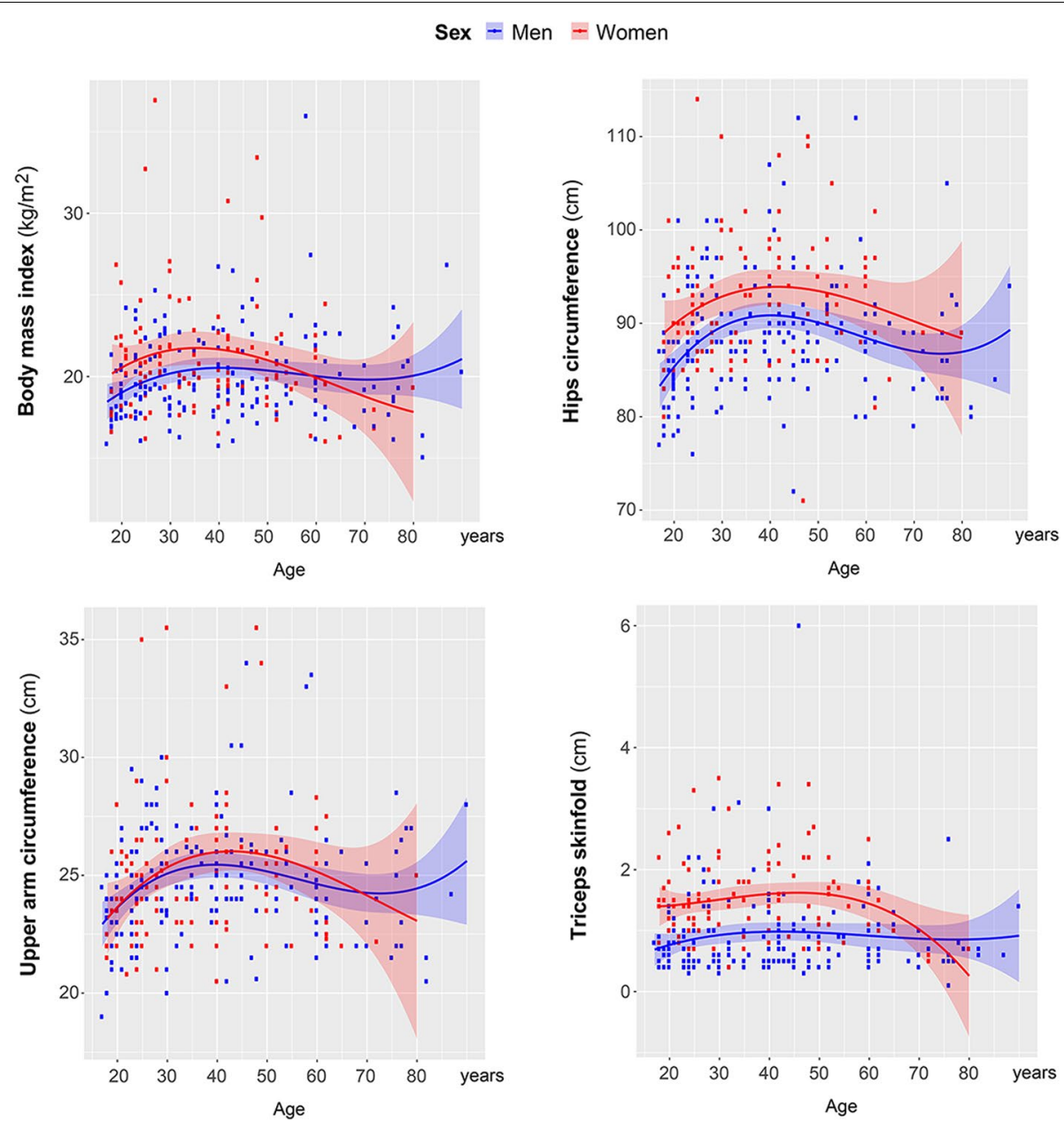

Fig. 7 Female-specific body parameters. Results of the regression analysis per each parameter: body mass index: cubic model (men: $R^{2}=0.046, p$ $=0.043$; women: $R^{2}=0.044, p=0.173$ ); hips circumference: cubic model (men: $R^{2}=0.112, p<0.001$; women: $\left.R^{2}=0.051, p=0.024\right)$; upper arm circumference: cubic model (men: $R^{2}=0.082, p=0.002$; women: $R^{2}=0.050, p=0.120$ ); triceps skinfold: cubic model (men: $R^{2}=0.016, p=0.406$; women: $\left.R^{2}=0.063, p=0.056\right)$

Table 3 Body sexual dimorphism in young- and mid-adult Maasai

\begin{tabular}{lllll}
\hline Dependent variable: sex (female) & & & \\
\hline Predictors & $\boldsymbol{B}$ & $\boldsymbol{P}$ & $\mathbf{p}$ (model) & $\boldsymbol{R}^{\mathbf{2}}$ \\
\hline Body height & -17.311 & 0.001 & $<0.001$ & 0.881 \\
Under-chest circumference & -0.336 & $<0.001$ & & \\
Handgrip strength & -0.234 & 0.001 & & \\
Hips circumference & 0.484 & $<0.001$ & & \\
\hline
\end{tabular}

Binary logistic regression (stepwise, forward Wald algorithm). Independent variables, which entered the analysis: body height, body weight, BMI, handgrip strength, wrist diameter, upper arm circumference, triceps skinfold, under-chest circumference, hips circumference, facial centroid size years age cohort. Geometric morphometric analysis revealed no considerable association of facial shape with body height either in men $(N=135$, var. expl. $=1 \%, p=$ $0.075)$, or women $(N=96$, var. expl. $=2 \%, p=0.092)$. At the same time, facial shape was significantly associated with facial centroid size in both sexes (men: $N=136$, var. expl. $=6 \%, p<0.001$; women: $N=96$, var. expl. $=7 \%, p$ $<0.001)$. Even after controlling for BMI, this association remained highly significant (men: $N=128$, var. expl. = $6 \%, p<0.001$; women: $N=91$, var. expl. $=6 \%, p<0.001$ ).

To assess quantitatively, which facial areas were most sensitive to allometric effects, we used multivariate analysis of covariance (MANCOVA), where the set of facial parameters (upper fWHR in four variants, total fWHR, lower fWHR, cheekbone prominence, mandibular index, nasal index, mouth shape, mouth-face index, heightto-width ratio of the eye) was assigned as dependent 
variables, and BMI and facial centroid size (CS) (or alternatively body height) were set as covariates. Results revealed no associations between facial parameters and body height for men. For women, there were very weak relation between body height and upper, total, and lower fWHR, with partial Eta ${ }^{2}$ not exceeding the level of 0.06; significance level for these parameters could not survive Bonferroni correction for testing 12 variables. Details can be found in Supplementary Table 1. Worth noting that without BMI control, facial parameters also were not related to body height (Suppl. Tab. 2).

However, a number of associations were revealed between facial indices and size of the face (CS) (Table 4, Fig. 8). Both in Maasai men and women, upper, total, and lower fWHR were significantly associated with facial centroid size, with larger faces having lower values of these parameters. Thus, larger faces in Maasai were characterized by narrower and prolonged in vertical direction shape.
These results suggest that body height and facial size are not directly associated in Maasai (especially in men), and allometric effect on facial traits occurs locally: face growth results in the narrower and prolonged in vertical direction faces, but is not strongly related to body growth. Analysis of association between body height and facial CS confirmed that such tendency was especially pronounced in men: body height explained only around $4 \%$ of variance in male facial centroid size (linear regression: Beta $=0.207, R^{2}=0.043, p=0.016$ ), whereas for women this relation was stronger (Beta $=0.324, R^{2}=$ $0.105, p=0.001$ ).

\section{Association between facial and body parameters}

The association between facial and body parameters were also tested pooling young- and mid-adult cohorts (age range 17-50 years), with analysis performed controlling for BMI. For this purpose, MANCOVA was applied, where the full set of 12 facial indices was assigned as dependent variables, and BMI and each of the body

Table 4 Association between facial traits and facial centroid size in Maasai (controlled for BMI)

\begin{tabular}{|c|c|c|c|c|c|}
\hline Covariate & Dependent variables & Definition & $F$ & Partial Eta ${ }^{2}$ & Sig. \\
\hline \multicolumn{6}{|l|}{ Men } \\
\hline \multirow[t]{12}{*}{ Facial CS } & Upper fWHR & $|Z y-Z y| /|N-S t o|$ & 6.09 & 0.046 & 0.015 \\
\hline & & $|Z y-Z y| /|G|-S t o \mid$ & 16.84 & 0.117 & $<0.001^{*}$ \\
\hline & & $|Z y-Z y| /|N-L s|$ & 5.90 & 0.045 & 0.017 \\
\hline & & $|Z y-Z y| /|G I-L s|$ & 16.34 & 0.114 & $<0.001 *$ \\
\hline & Total fWHR & $|Z y-Z y| /|N-G n|$ & 22.3 & 0.150 & $<0.001^{*}$ \\
\hline & Lower fWHR & $|Z y-Z y| /|S n-G n|$ & 19.1 & 0.132 & $<0.001 *$ \\
\hline & Cheekbone prominence & $|Z y-Z y| /|G o-G o|$ & 5.61 & 0.039 & 0.025 \\
\hline & Mandibular index & $\mid$ Go-Go|/|Sto-Gn| & 7.01 & 0.054 & 0.008 \\
\hline & Nasal index & $|\mathrm{Al}-\mathrm{A}||/| \mathrm{N}-\mathrm{Sn} \mid$ & 0.88 & 0.007 & 0.350 \\
\hline & Mouth shape & $|\mathrm{Ls}-\mathrm{Li}| /|\mathrm{Ch}-\mathrm{Ch}|$ & 3.61 & 0.028 & 0.060 \\
\hline & Mouth-face index & $|\mathrm{Ch}-\mathrm{Ch}| /|\mathrm{Zy}-\mathrm{Zy}|$ & 3.95 & 0.030 & 0.050 \\
\hline & Height-to-width ratio of the eye (mean) & $|\mathrm{Ps}-\mathrm{Pi}| /|\mathrm{Ex}-\mathrm{En}|$ & 3.02 & 0.023 & 0.084 \\
\hline \multicolumn{6}{|l|}{ Women } \\
\hline \multirow[t]{12}{*}{ Facial CS } & Upper fWHR & $|Z y-Z y| /|N-S t o|$ & 13.03 & 0.128 & $0.001 *$ \\
\hline & & $|Z y-Z y| /|G l-S t o|$ & 20.78 & 0.189 & $<0.001^{*}$ \\
\hline & & $|Z y-Z y| /|N-L s|$ & 11.25 & 0.112 & $0.001^{*}$ \\
\hline & & $|Z y-Z y| /|G|-L s \mid$ & 19.92 & 0.183 & $<0.001 *$ \\
\hline & Total fWHR & $|Z y-Z y| /|N-G n|$ & 18.72 & 0.174 & $<0.001 *$ \\
\hline & Lower fWHR & $|Z y-Z y| /|S n-G n|$ & 11.96 & 0.119 & $0.001^{*}$ \\
\hline & Cheekbone prominence & $|Z y-Z y| /|G o-G o|$ & 0.60 & 0.006 & 0.452 \\
\hline & Mandibular index & $\mid$ Go-Go| / |Sto-Gn| & 6.35 & 0.066 & 0.014 \\
\hline & Nasal index & $|\mathrm{Al}-\mathrm{A}||/| \mathrm{N}-\mathrm{Sn} \mid$ & 0.46 & 0.005 & 0.500 \\
\hline & Mouth shape & |Ls-Li|/|Ch-Ch| & 0.70 & 0.008 & 0.405 \\
\hline & Mouth-face index & $|\mathrm{Ch}-\mathrm{Ch}| /|\mathrm{Zy}-\mathrm{Zy}|$ & 0.26 & 0.003 & 0.613 \\
\hline & Height-to-width ratio of the eye (mean) & $|\mathrm{Ps}-\mathrm{Pi}| /|\mathrm{Ex}-\mathrm{En}|$ & 0.47 & 0.005 & 0.495 \\
\hline
\end{tabular}

MANCOVA results are presented. Dependent variables: facial traits; independent variables: 1) BMI, 2) facial centroid size (CS). Effect size (partial Eta ${ }^{2}$ ) and significance level $(p)$ are presented only for CS (after controlling for BMI). Definitions of the facial landmarks used for facial traits calculation can be found in Fig. 1. Significant associations, which survived Bonferroni correction for testing 12 variables are marked with *, and presented in bold 

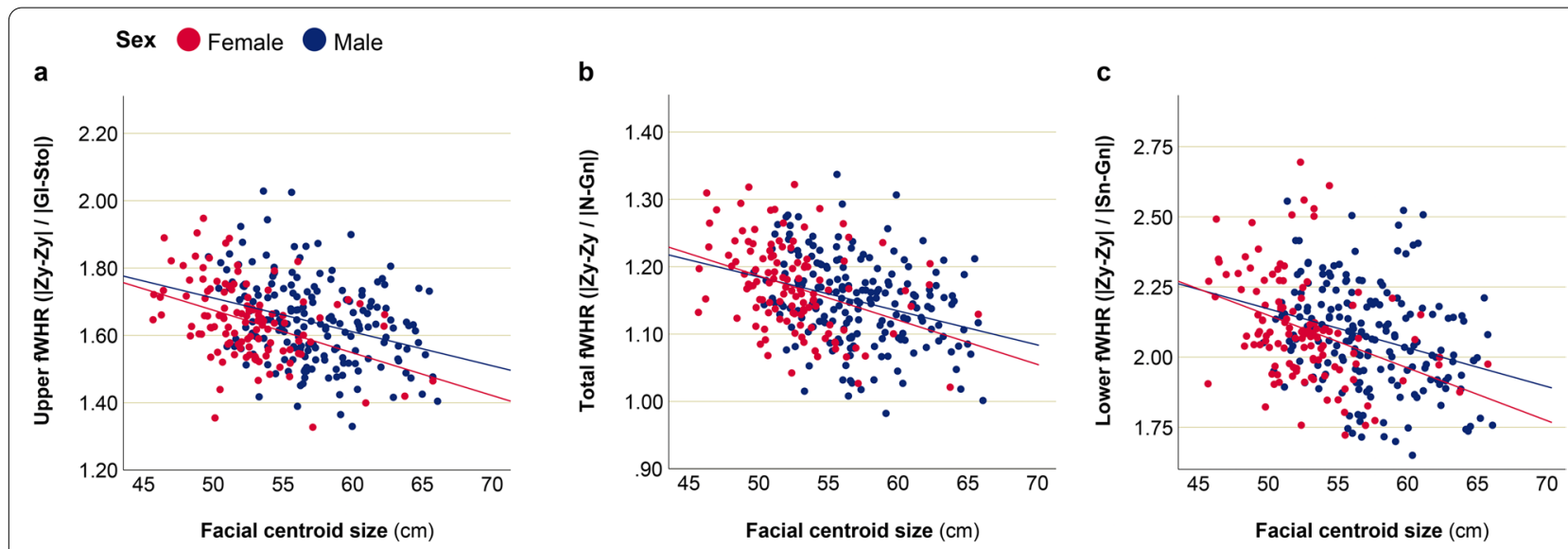

Fig. 8 Association between fWHRs and facial centroid size in Maasai men and women (controlled for BMI). a men: $R^{2}=0.095$, women: $R^{2}=0.164 ; \mathbf{b}$ men: $R^{2}=0.090$, women: $R^{2}=0.136$; c men: $R^{2}=0.085$, women: $R^{2}=0.132$

measures were set as covariates. The list of body parameters used for association with facial traits was restricted to those, which represent skeletal and muscular development (wrist diameter, upper arm circumference, underchest circumference, hip circumference), rather than fat deposition. Association between facial shape and handgrip strength in the same Maasai sample has been previously demonstrated and discussed in detail in other our publication [120]; therefore, we do not directly focus on this parameter here, but rather estimate it through other body traits, which were not tested before. Analysis was held separately for men and women.

The results revealed associations between upper arm circumference, upper fWHR, and cheekbone prominence for men, as well as upper arm circumference and nasal index for women. The under-chest circumference was also associated with cheekbone prominence in men. All these associations stood significant after Bonferroni correction for testing 12 variables (Table 5; Fig. 9). Details on all parameters can be found in Supplementary Table 3.

According to obtained results, larger upper arm circumference of the right hand was significantly associated with higher upper fWHR (measured as $|\mathrm{Zy}-\mathrm{Zy}| / \mid \mathrm{N}$-Sto $\mid$ ) and relatively higher bigonial width (i.e., lower cheekbone prominence measured as $|\mathrm{Zy}-\mathrm{Zy}| /|\mathrm{Go}-\mathrm{Go}|)$ in Maasai men. For women, this relation was not significant. Relatively higher bigonial width was also detected for men with larger under-chest circumference. This relation was also not statistically significant for women. However, upper arm circumference was positively related to relative nasal width (nasal index) in Maasai women, whereas for men this association was not significant.

In our earlier study, it was demonstrated that physical strength of Maasai was positively associated with facial width, both in zygomatic and bigonial areas [121]. We proposed that upper arm and under-chest circumferences could be viewed as parameters related to male muscular and skeletal development, and thus could be associated with physical strength. To test this assumption, we analyzed relationship between handgrip strength and body parameters using linear regression with stepwise (forward) inclusion of predictors. The analysis was held for men and women separately, and the list of predictors included body height, body

Table 5 Association between facial traits and body parameters in Maasai (controlled for BMI)

\begin{tabular}{|c|c|c|c|c|c|}
\hline Predictor & Dependent variables & Definition & $F$ & Partial Eta ${ }^{2}$ & Sig. \\
\hline \multicolumn{6}{|l|}{ Men } \\
\hline \multirow[t]{2}{*}{ Upper arm circumference } & Upper fWHR & $|Z y-Z y| /|N-S t o|$ & 10.20 & 0.075 & 0.002 \\
\hline & Cheekbone prominence & $|Z y-Z y| /|G o-G o|$ & 9.02 & 0.067 & 0.003 \\
\hline Under-chest circumference & Cheekbone prominence & $|Z y-Z y| /|G o-G o|$ & 9.90 & 0.073 & 0.002 \\
\hline \multicolumn{6}{|l|}{ Women } \\
\hline Upper arm circumference & Nasal index & $|\mathrm{Al}-\mathrm{Al}| /|\mathrm{N}-\mathrm{Sn}|$ & 11.84 & 0.119 & 0.001 \\
\hline
\end{tabular}

Only significant results of MANCOVA are presented. Dependent variables: facial traits; independent variables: 1) BMI, 2) each of body parameters. Effect size (partial Eta ${ }^{2}$ ) and significance level $(p)$ are presented only for each body parameter (after controlling for BMI). Definitions of the facial landmarks used for facial traits calculation can be found in Fig. 1. All presented associations stood significant after Bonferroni correction for testing 12 variables. Full results can be found in Supplementary Tab. 3 

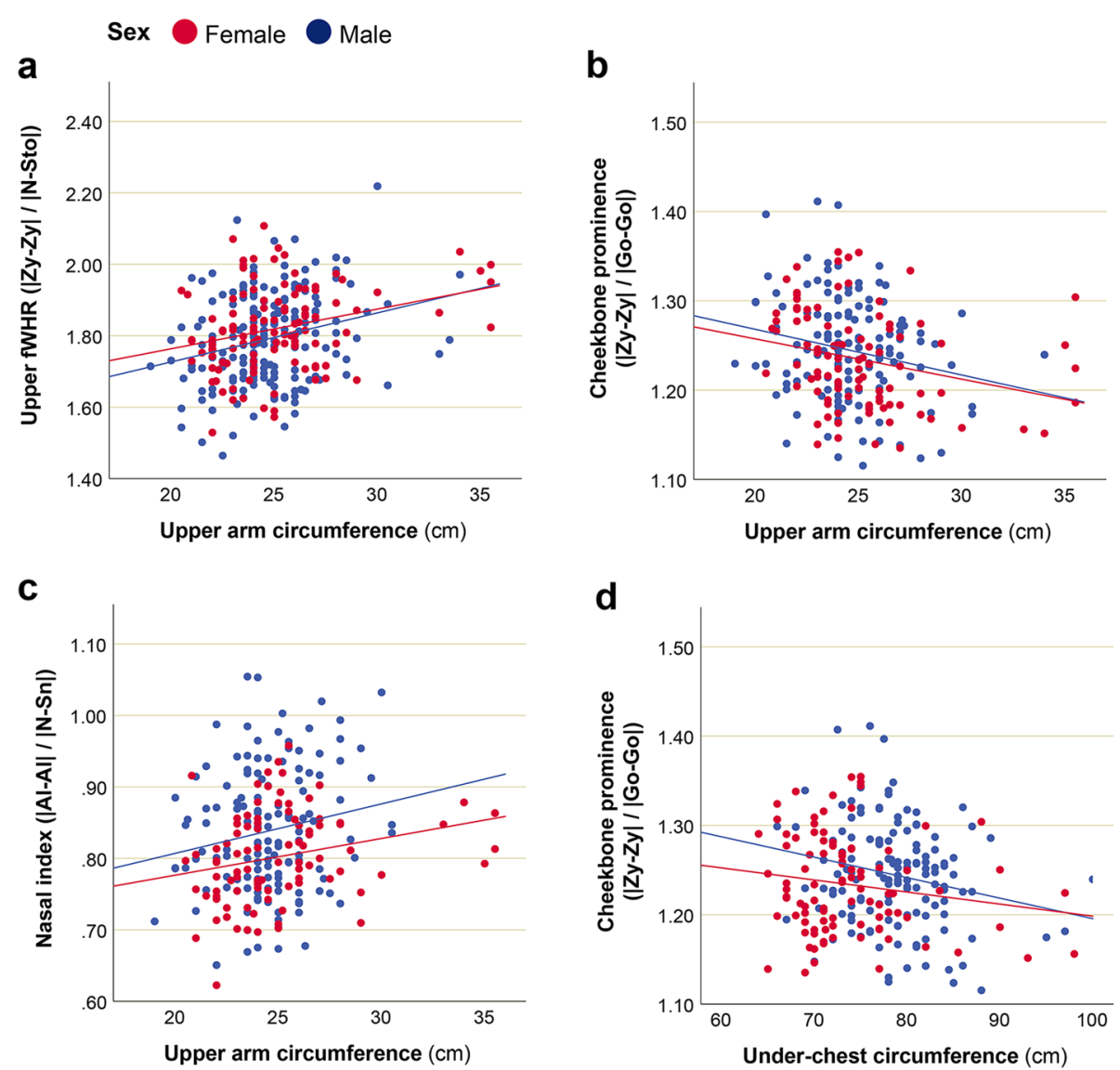

Fig. 9 Association between facial traits and body parameters in young- and mid-adult Maasai. a Men: $R^{2}=0.076$, women: $R^{2}=0.072 ; \mathbf{b}$ men: $R^{2}=$ 0.042, women: $R^{2}=0.069 ; \mathbf{c}$ men: $R^{2}=0.034$, women: $R^{2}=0.067$; d men: $R^{2}=0.045$, women: $R^{2}=0.026$

Table 6 Association between handgrip strength and body parameters in Maasai men

\begin{tabular}{lllll}
\hline \multicolumn{5}{l}{ Dependent variable: handgrip strength in men } \\
\hline Predictors & $\boldsymbol{B}$ & $\boldsymbol{P}$ & $\mathbf{p}$ (model) & $\boldsymbol{R}^{\mathbf{2}}$ \\
\hline Upper arm circumference & 1.697 & $<0.001$ & $<0.001$ & 0.268 \\
Wrist circumference & 0.564 & 0.002 & & \\
Triceps skinfold & -0.359 & 0.022 & & \\
\hline
\end{tabular}

Linear regression with stepwise inclusion of predictors (forward algorithm). Independent variables, which entered the analysis: body height, body weight, $\mathrm{BMI}$, wrist diameter, upper arm circumference, triceps skinfold, under-chest circumference, hips circumference, facial centroid size

weight, BMI, wrist diameter, upper arm circumference, triceps skinfold, under-chest circumference, hips circumference, and facial centroid size. Regression model for men was terminated at step 3, resulting in 3 predictors (upper arm circumference, wrist circumference, and triceps skinfold), which together explained around $27 \%$ of variance in handgrip strength $(p<0.001)$
(Table 6). For women, no significant associations were revealed.

Thus, according to the results, higher handgrip strength in men was positively associated with upper arm and wrist circumferences, and negatively with triceps skinfold. This, at least partially, corresponds to our expectations, confirming that more physically developed (and strong) Maasai men had relatively wider faces, both in mid- and lower facial areas. Although, these traits were not generally sex-specific (Table 1).

\section{Discussion}

In this study, it was demonstrated that sexual facial dimorphism in Maasai is rather low, compared to Europeans and Asians $[38,124]$, and sex explains $1.8 \%$ of the total variance of facial shape in the whole sample (for instance, in Buryats, a Mongolian population of Southern Siberia, sex explains $20 \%$ of the total facial shape variance, which was demonstrated using the same configuration of facial landmarks as in the present study [124]). When the three age cohorts of Maasai were tested 
separately, it was found that sex differences in facial morphology were minimal $(2 \%)$ in the youngest age cohort, and increase with age, gaining up to $4 \%$ in in elder-adults age cohort. However, after controlling for BMI, sexual dimorphism in Maasai facial shape within the mid-adult cohort decreased. Despite the small dimorphism, the morphometric data pointed to relatively narrower and vertically prolonged faces, slightly wider noses, narrowerset and lower eyebrows, slightly wider mouth, and higher forehead hairline in males. Female faces were wider, especially in the aria of bigonial width, shorter and rounded, their noses were smaller both in width and height, and these differences were maximal in mid-age cohort. As for the more rounded faces and smaller noses, the Maasai women were similar to women from Caucasian origin from Slovenia [134]. Both in Maasai and Caucasian sample, the gender-dependent characteristics were even more pronounced in the middle-age and older adults [134]. The data on sexual dimorphism in Maasai faces are in certain contradiction to previous findings from Caucasian populations, for which significant sex dimorphism in facial shape was reported [134, 135]. Maasai women have wider faces compared to men, and this tendency remained visible with control for BMI. Similar sexual differences were reported by us earlier in Buryats, the Mongolian origin people from Southern Siberia [37]. On the contrary, in Caucasian and majority of studied Asian populations, men usually have relatively wider faces compared to women $[33,70]$ (see review on 32 populations: [67]).

Men and women Maasai demonstrate age-related differences in changes of facial shape. Such changes were especially evident in women between 17 and 29 years of age. Our data suggest that, at least to some degree, the increase of facial sex dimorphism with age may be due to the effect of BMI (higher in women, compared to men, as well as increasing in women with age). Aging processes in older age-cohort affected male facial morphology more compared to women. Men demonstrate the degradation of the lower lip vermillion, further narrowing of the lower face and decrease of the sex-specific male morphology in the eyebrows and nasal regions. We conclude that the most sexually dimorphic regions of the face in Maasai were the lower jaw and the nose.

One of the goals of our study was to address the debates on sex-typical variation in fWHR and its' evolutionary origin. Recently published paper by Hodges-Simeon with co-authors [72] based on data from Caucasian origin (from 3 to 40 years) and Bolivian Tsimane (from 7 to 21 years) samples of men and women tested the applicability of four variants of fWHR measurements and demonstrated that fWHR lower (including lower jaw) exhibited both adult sex differences, and the classic pattern of ontogeny for human secondary sexual characteristics (greater lower-face growth in male adolescents relative to females). In our study, we calculated six variants of fWHR (including four variants of upper fWHR, total, and lower fWHR), but none of them revealed significant sexual dimorphism. The Maasai women on average, with control for BMI, had slightly higher (although non-significant) values of upper fWHR. Taking the data from other populations [38, 75-0], we conclude that sexual dimorphism in upper fWHR may not be universal for humans. Few years earlier, Kramer has arrived to identical conclusion, on the basis of meta-analysis of human skull [71]. And given resent data from relatively big sample of 131 chimpanzees, represented three subspecies (Pan troglodytes verus, $P$. $t$. schweinfurthii, $P$. $t$. troglodytes), fWHR may not be considered as sex-related trait in this species either [97].

To what extent facial dimorphism, particularly masculinity traits, may be related to reproduction in Maasai population remained to be tested. However, the data from two traditional non-western societies-the Agta of Philippines, egalitarian forest nomadic hunter gatherers, practicing monogamous marriages, bilocal and exogamic, and monogamous Maya of western Belize, practicing mixture of slash-and-burn agriculture and paid labour, with high rate of arranged marriages, and patrilocal or neolocal residence-provide no evidence that offspring of males with higher facial masculinity survive better [136]. Recent meta-analysis testing relationships between sexually dimorphic traits and reproduction in men revealed no association between facial masculinity and either mating or reproduction $[29,137]$.

Our findings on low level of facial shape sexual dimorphism are in total agreement with findings reported by other scholars for other African populations, particularly Namibian Nama and Cameroonian Bantu [38]. The lack of sexual dimorphism in shape may be compensated by sex differences in color, preferences for lighter skin in females were found in some African populations [138140]. Besides, in Cameroonian females, the skin lightness was positively correlated with perceived femininity. Skin lightness in the Cameroonian, Iranian, and Turkish male faces was negatively correlated with masculinity [141]. Hence, in non-European populations, the facial shape dimorphism may be in certain association with skin color.

Counter to the low facial dimorphism in Maasai, our data revealed quite large body sexual dimorphism, with body height as the most noticeable contributor to it. This parameter together with the three others (under-chest, hips circumferences, and handgrip strength) predicted the sex in Maasai population with $88 \%$ of reliability. The comparison of our data on the degree of sexual 
dimorphism in body height with data on other sub-Saharan populations available, including another Maasai sample [142], confirms that Maasai are among the populations with high level of sex differences in body height in this region (Fig. 10).

Interestingly, effects of static allometry on facial traits of Maasai were mostly defined by the processes of the face growth, rather than related to the growth of the whole body (body height). Earlier studies by other authors focusing on the representatives of European populations come to somewhat contradictive conclusions about the effects of body and face sizes on the facial traits. The study by Mitteroecker with coauthors [46] revealed no significant associations between facial centroid size and facial shape in men, whereas association with body height was significant and explained around $7 \%$ of variation in facial traits. Other study in Germans revealed a relation between body height and facial shape, with taller men having narrower and more vertically prolonged lower face [45]. At the same time, the study conducted among Czech students revealed an association between facial size and sexually dimorphic facial traits [143]. The direction of changes in the facial shape with increase of the facial size in Czech study was in line with our findings: larger faces were more prolonged in vertical direction. It was previously demonstrated that head size (head circumference) is correlated with body height in humans [144]. However, correlation between head size and facial shape is expected to be mediated by the factor of the head shape itself. For instance, patterns of integration between facial and basal cranium with respect to brachycephalic and dolichocephalic features may lead to different width-to-height ratios of the faces, which is deeply rooted in human phylogeny [145]. Hence, in the case of dolichocephalic condition, increase of head (and facial) size may result in decrease of fWHRs, which we observed in Maasai. One of the current studies comparing several world populations on facial sexual dimorphism and allometry (measured through body height) suggests that effects of body height on sexual dimorphism of facial shape vary dramatically between people of different descent [38]. In that study, it was demonstrated that both allometric and non-allometric facial sexual dimorphism may largely differ even among populations of common geographical origin (within Africans, Europeans, South-Americans), with African populations generally having very low level of facial sexual dimorphism and its association with body height. The reasons behind such differences remain unclear and deserve to be carefully inspected in the future.

Our results revealed significantly higher wrist diameter in men, and BMI, hips circumference, upper arm circumference, and triceps skinfold in women. Although, according to BMI both men and women Maasai were quite skinny, but women generally had more fat, as judged from triceps skinfolds. Other studies suggest that

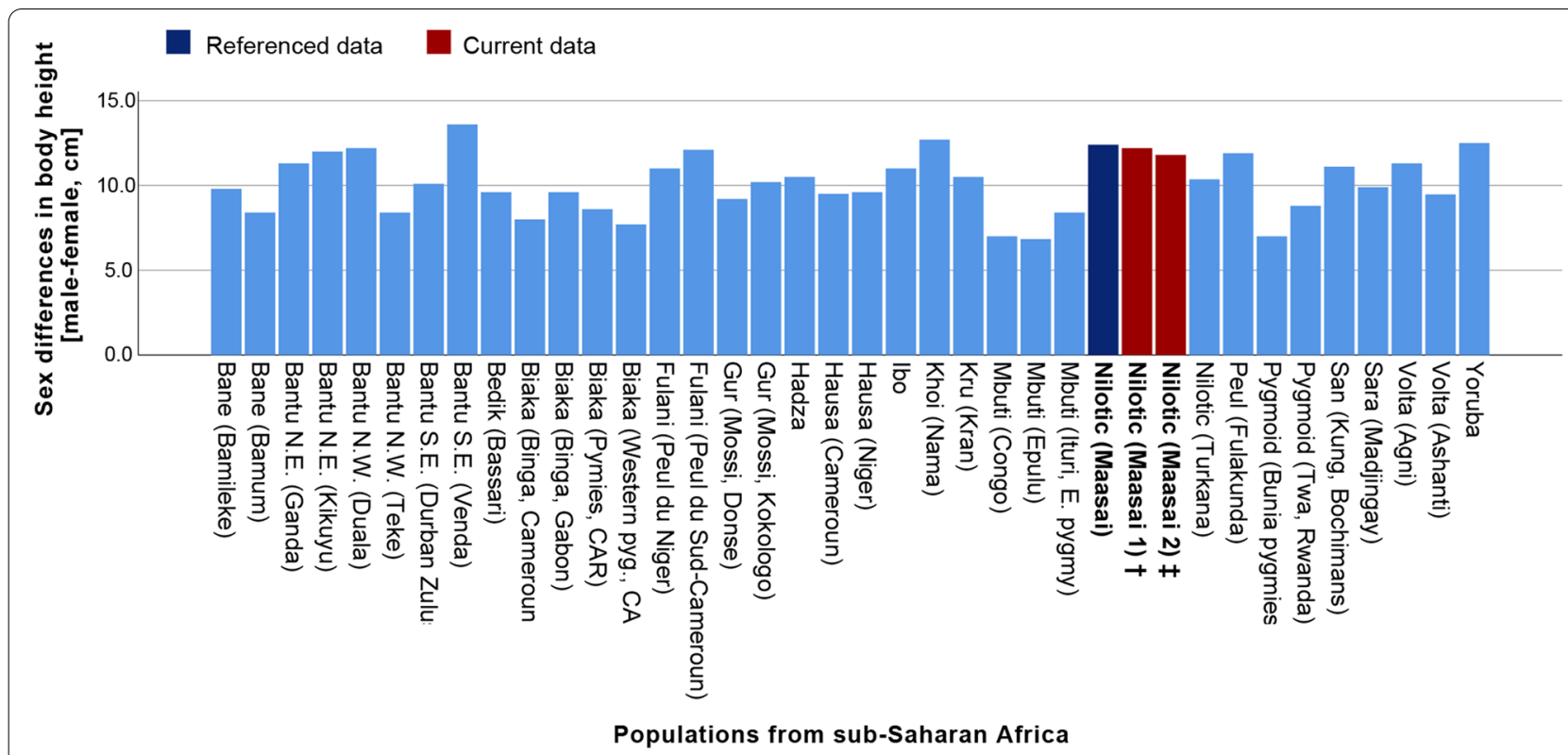

Fig. 10 Distribution of sex differences in body height in African sub-Saharan populations, with our data on young-and mid-adults Maasai included. Figure created based on Gustafsson, Lindenfors, 2004 [136]. ${ }^{\dagger}$ Maasai 1: data from the current sample (age: 17-29 years). ${ }^{\ddagger}$ Maasai 2: data from the current sample (age: $30-50$ years) 
African men generally have higher percentage of fat-free mass (mainly muscle mass) than women, indicating that under-and-normal weight men likely had a substantial amount of muscle [41, 146], and Maasai men may well fit these assumptions.

Earlier, we have shown the association between physical strength (as measured by HGS) and facial shape for the same Maasai sample [121]. Current study adds more details on these relationships by specifying associations between facial parameters and HGS-related body traits. The strong intrasexual competition in Maasai may be of different intensity in men and women, as well as vary in different age cohorts. Intrasexual competition in men may be most overt during murran stage, as at this time young men establish their social relationships, social status, and gain prestige among peers, while at later stages physical strength may be of less importance compared to social skills (including ability for conflict resolutions and mediation conflicts of others), and successful cattle breeding. Physical strength, which may be a proxy to good health, may be highly important for women during the whole life span, given high energetic costs of pregnancy and breastfeeding, strong competition with other co-wives for resources, and various hard household duties.

Data on healthy and physically active men from western population demonstrate significant relationship between male stature and the change in testosterone levels, and no link between body height and circulating testosterone levels in general. Hence, height may indicate males' adaptive capabilities to physiologically mobilize their bodies under challenging situations [147]. This may be particularly important in traditional populations, which were not long ago exposed, or still being exposed to raids, carnivorous pressure, and intrasexual contests. Maasai being one of such examples. Some findings suggest that prenatal testosterone exposure may affect the sexually dimorphic facial morphology [17], and androgens in males could contribute to facial sexual dimorphism both before and after puberty [34]. The data from two traditional East African populations, one of which is seminomadic pastoralists similar to Maasai in their ecology and cultural patterns (the Datoga), pointed to the potential role of androgen receptor gene polymorphism in male aggression and reproduction (number of offspring born) [148, 149]. To what extent sexual dimorphism may be a result of selection for attractive partners in Maasai remained a question. In reality, up-till now most marriages in Maasai (especially for women) are arranged by their families. Traditionally, girls being married around the age of 12-13 years, that is during early adolescence, and age differences between spouses are rarely less than 10-15 years. The Maasai remained polygynous, with naturally high fertility profile $(\mathrm{M}=5.5$ offspring with variation from 2 to 10 per women of post-reproductive age in our sample). High level of pathogen pressure, as well as various environmental threats (including wild animals), remained to be actual selective forces nowadays, and were even more efficient in the past history of Maasai.

Our results demonstrate that facial and body sexual dimorphism may not be directly interrelated in humans, and suggest that in traditional populations, with high level of intrasexual competition among males and high level polygyny body sexual dimorphism, as well as section for height, strength and muscularity may be the men's priority, whereas facial dimorphism may not be beneficial for survival. It is notable that in populations with large sex differences in body parameters, facial shape differences between men and women can be very low. In recent meta-analysis, Lidborg with co-authors [137] came to the conclusion that body muscularity/strength can be considered sexually selected in human males, and may predict both mating and reproductive success, whereas facial masculinity does not.

We hypothesize that observed body sexual dimorphism in Maasai population may be a compromise between intrasexual competition in males and mate choice selection. Maasai of Ngorongoro remained a population with traditional life-style and natural reproductive profile, muscularity and strength in men continue to be of primary importance for successful cattle breeding, and family protection. While higher body adiposity, as well as waist to hips ratio in women remained to be important prerequisite for successful childbearing and breastfeeding under conditions of limited access to medical help. In fact, earlier we have demonstrated that physically stronger Maasai men were rated as more attractive by women from this same population (see [121]).

It may be highly important to differentiate between body and facial dimorphism and to find the reasons for its' disproportional expression. The question is what were the driving forces for shaping sexually dimorphic faces and bodies? Selection of female partners with more feminine faces, or selection of younger females? This is especially relevant in the case of traditional populations, where calendar age is not known. Younger looking females are usually more feminine in appearance. This is true both for facial shape as well as body shape [150]. Of sure fertility issues are much more relevant to women than to men, given a limited period till menopause. For men, it is more beneficial to obtain a wife with longer, and potentially more successful reproductive history. In relation to facial ques, as recently demonstrated by Karel Kleisner with co-authors, " the association between sexual shape dimorphism and attractiveness is moderate for women and weak (or absent) for men. Analysis that 
distinguishes between allometric and non-allometric components reveals that non-allometric facial dimorphism is preferred in women's faces but not in faces of men. This might be due to different regimes of ongoing sexual selection acting on men, such as stronger intersexual selection for body height and more intense intrasexual physical competition, compared with women" [38]. Intrasexual competition in men may take direct and indirect forms, but in both cases higher masculinity may be selected for. For instance, in hunter-gatherers, men's lower (more masculine) voice pitch may be associated with better hunting reputation [151]. But, lower voice pitch may be a proxy to androgen level, while, in turn, facial masculinity and androgen level are positively associated. Another environmental pressure is a high pathogen level, associated with high mortality rate of children. And this factor may be one of the explanations of variations in preference for masculinity observed cross-culturally [152]. Some studies demonstrated that females prefer more masculine male partners, and males, in turn, more feminine looking females in such environment or in the absence of high-quality medical help [153]. It remains to be found out in the future, which sexually dimorphic traits may enhance individual survival probability to different degrees in males and females and show lesser variations between populations of modern humankind [34].

Sociocultural environment may cause substantial pressure on the perception of attractiveness as well. Particularly, facial averageness hypothesis fitted the recently obtained results [154]. Importantly, according to Pavlovič with co-authors, the impact of sexual shape dimorphism on attractiveness was marginal, and found only in Czech European male raters. Earlier, the group of authors presented the data on preferences for sexually dimorphic faces from 12 populations with very diverse levels of economic development [155], and challenge the hypothesis, according to which the "facial dimorphism was an important ancestral signal of heritable mate value." According to these authors, preferences for facial sexual dimorphism are more evident in large-scale, urban societies, and may be evolutionary novel behavior originated since the time, when people started to interact with large numbers of unfamiliar faces on daily basis.

\section{Conclusions}

Facial shape sex dimorphism in Maasai is very low: sex explained only $1.8 \%$ of the total variance. Facial width-to-height ratio (fWHR), measured in six known variants, revealed no significant sex differences. On the contrary, the body sexual dimorphism in Maasai is high, with men being significantly taller, with larger wrist diameter and hand grip strength, and women having higher BMI, hips circumferences, upper arm circumferences, triceps skinfolds. There were practically no associations between facial and body traits, hence, facial and body sexual dimorphisms were not interconnected. The allometric effects on facial traits were mostly related to the face growth, rather than the growth of the whole body. Obtained results clearly demonstrate that under certain conditions the degrees of facial and body sexual dimorphisms may not be interrelated, suggesting different selective processes operating on facial and body sex-specific morphology. Preferences for sexually dimorphic facial and body traits need to be tested cross-culturally in more detail in the future as well.

\section{Abbreviations}

ANCOVA: Analysis of covariance; BMI: Body mass index; COSTECH: Tanzania Commission for Science and Technology; CS: Centroid size; FH: Frankfort Horizontal Plane; fWHR: Facial width-to-height ratio; HGS: Handgrip strength; ICC: Intraclass correlation coefficients; MANCOVA: Multivariate analysis of covariance; NCA: Ngorongoro Conservation Area; SD: Standard deviation.

\section{Supplementary Information}

The online version contains supplementary material available at https://doi. org/10.1186/s40101-021-00276-8.

Additional file 1: Supplementary Table 1. Association between facial traits and body height in Maasai (controlled for BMI).

Additional file 2: Supplementary Table 2. Association between facial traits and body height in Maasai (without control for BMI).

Additional file 3: Supplementary Table 3. Association between facial traits and body parameters in Maasai (controlled for BMI).

\section{Acknowledgements}

This study was conducted in line with research permit obtained from COSTECH. We thank the NCA administration for permission to conduct this study in Ngorongoro, and for Prof. Audax Mabulla assistance with logistics. We are grateful to our field assistant Samson Koromo for his help and friendship, and the Maasai participants for tolerance and cooperation.

\section{Authors' contributions}

$M B$ and $V R$ designed the study. MB collected the data. VR and MB analyzed the data. VR and AM implemented geometric morphometrics. MB and VR drafted the manuscript. All authors have read and agreed to the published version of the manuscript.

\section{Funding}

The study was supported by Russian Science Foundation, project 18-18-00075.

\section{Availability of data and materials}

The data that support the findings of this study are available from the corresponding author upon reasonable request.

\section{Declarations}

Ethics approval and consent to participate

The study was conducted according to the principles of the Declaration of Helsinki. The population studied was illiterate and therefore a written consent could not be obtained. The participants gave verbal consents and were told that their participation was voluntary and that they could withdraw from the study at any time. The study protocol and consent procedure received ethical approval from the Ethics Committee of Moscow State University; research 
permit was obtained from the Tanzania Commission for Science and Technology (COSTECH) and administration of Ngorongoro Conservation Area (NCA).

\section{Consent for publication}

Not applicable.

\section{Competing interests}

The authors declare no competing interests.

\section{Author details}

'Institute of Ethnology and Anthropology, Russian Academy of Sciences, Moscow 119334, Russia. ${ }^{2}$ The National Research University Higher School of Economics, Moscow 101000, Russia. ${ }^{3}$ Russian State University for the Humanities, Moscow 125047, Russia.

Received: 4 October 2021 Accepted: 10 December 2021 Published online: 07 January 2022

\section{References}

1. Darwin C. The descent of man and selection in relation to Ser. London: Murray; 1871.

2. Jones AG, Ratterman NL. Mate choice and sexual selection: what have we learned since Darwin? P Natl Acad Sci USA. 2009;106(Supplement 1):10001-8. https://doi.org/10.1073/pnas.0901129106.

3. Geary DC. Now you see them, and now you don't: an evolutionarily informed model of environmental influences on human sex differences. Neurosci Biobehav R. 2021;125:26-32. https://doi.org/10.1016/j. neubiorev.2021.02.020.

4. Clarkson TR, Sidari MJ, Sains R, Alexander M, Harrison M, Mefodeva $\checkmark$, et al. A multivariate analysis of women's mating strategies and sexual selection on men's facial morphology. R Soc Open Sci. 2020;7(1):191209. https://doi.org/10.1098/rsos.191209.

5. Jones $\mathrm{D}$, Brace $\mathrm{CL}$, Jankowiak W, Laland KN, Musselman LE, Langlois JH, et al. Sexual selection, physical attractiveness, and facial neoteny: crosscultural evidence and implications [and comments and reply]. Curr Anthropol. 1995;36(5):723-48.

6. Miller GF. How mate choice shaped human nature: a review of sexual selection and human evolution. In: Crawford C, Crebs DL, editors. Handbook of evolutionary psychology: Ideas, issues, and applications. Mahwah, New Jersey: Lawrence Erlbaum Associates; 1998. p. 87-129.

7. Perrett DI, Lee KJ, Penton-Voak I, Rowland D, Yoshikawa S, Burt DM, et al. Effects of sexual dimorphism on facial attractiveness. Nature. 1998;394(6696):884-7. https://doi.org/10.1038/29772.

8. Dunsworth HM. Expanding the evolutionary explanations for sex differences in the human skeleton. Evol Anthropol. 2020;29(3):108-16. https://doi.org/10.1002/evan.21834.

9. Bardin CW, Catterall JF. Testosterone: a major determinant of extragenital sexual dimorphism. Science. 1981;211(4488):1285-94 http://www. jstor.org/stable/1685305.

10. Fink B, Grammer K, Mitteroecker P, Gunz P, Schaefer K, Bookstein FL, et al. Second to fourth digit ratio and face shape. P Roy Soc B-Biol Sci. 2005;272(1576):1995-2001. https://doi.org/10.1098/rspb.2005.3179.

11. Law Smith MJ, Perrett DI, Jones BC, Cornwell RE, Moore FR, Feinberg DR, et al. Facial appearance is a cue to oestrogen levels in women. P Roy Soc B-Biol Sci. 2006;273(1583):135-40. https://doi.org/10.1098/rspb. 2005.3296.

12. Lefevre CE, Lewis GJ, Perrett DI, Penke L. Telling facial metrics: facial width is associated with testosterone levels in men. Evol Hum Behav. 2013;34(4):273-9. https://doi.org/10.1016/j.evolhumbehav.2013.03.005.

13. Marečková K, Chakravarty MM, Lawrence C, Leonard G, Perusse D, Perron $\mathrm{M}$, et al. Identifying craniofacial features associated with prenatal exposure to androgens and testing their relationship with brain development. Brain Struct Funct. 2015;220(6):3233-44. https://doi.org/ 10.1007/s00429-014-0852-3

14. Meindl K, Windhager S, Wallner B, Schaefer K. Second-to-fourth digit ratio and facial shape in boys: the lower the digit ratio, the more robust the face. P Roy Soc B-Biol Sci. 2012;279(1737):2457-63. https://doi.org/ 10.1098/rspb.2011.2351.
15. Schaefer K, Fink B, Mitteroecker P, Neave N, Bookstein FL. Visualizing facial shape regression upon 2 nd to 4 th digit ratio and testosterone. Collegium Antropol. 2005;29(2):415-9.

16. Verdonck A, Gaethofs M, Carels C, de Zegher F. Effect of low-dose testosterone treatment on craniofacial growth in boys with delayed puberty. Eur J Orthodont. 1999;21(2):137-43. https://doi.org/10.1093/ ejo/21.6.711.

17. Whitehouse AJ, Gilani SZ, Shafait F, Mian A, Tan DW, Maybery $M T$, et al. Prenatal testosterone exposure is related to sexually dimorphic facial morphology in adulthood. P Roy Soc B-Biol Sci. 1816;2015(282):20151351. https://doi.org/10.1098/rspb.2015.1351.

18. Lopes-Ramos CM, Chen CY, Kuijjer ML, Paulson JN, Sonawane AR, Fagny $M$, et al. Sex differences in gene expression and regulatory networks across 29 human tissues. Cell Rep. 2020;31(12):107795. https://doi.org/ 10.1016/j.celrep.2020.107795.

19. Takahashi T, Iwasaki A. Sex differences in immune responses. Science. 2021;371(6527):347-8. https://doi.org/10.1126/science.abe7199.

20. Folstad I, Karter AJ. Parasites, bright males, and the immunocompetence handicap. Am Nat. 1992;139(3):603-22.

21. Bhatia A, Sekhon HK, Kaur G. Sex hormones and immune dimorphism. Sci World J. 2014;2014:159150.

22. Pennell LM, Galligan CL, Fish EN. Sex affects immunity. J Autoimmun. 2012;38(2-3):J282-91. https://doi.org/10.1016/j.jaut.2011.11.013.

23. Cunningham M, Gilkeson G. Estrogen receptors in immunity and autoimmunity. Clin Rev Allergy Immunol. 2011;40(1):66-73. https://doi.org/ 10.1007/s12016-010-8203-5.

24. Foo YZ, Simmons LW, Perrett DI, Holt PG, Eastwood PR, Rhodes G. Immune function during early adolescence positively predicts adult facial sexual dimorphism in both men and women. Evol Hum Behav. 2020;41(3):199-209. https://doi.org/10.1016/j.evolhumbehav.2020.02. 002.

25. Zuk M. The role of parasites in sexual selection: current evidence and future directions. Adv Stud Behav. 1992;21:39-68.

26. Dixson BJ, Little AC, Dixson HG, Brooks RC. Do prevailing environmental factors influence human preferences for facial morphology? Behav Ecol. 2017;28(5):1217-27. https://doi.org/10.1093/beheco/arx067.

27. Laland KN. Sexual selection with a culturally transmitted mating preference. Theor Popul Biol. 1994;45(1):1-15. https://doi.org/10.1006/tpbi. 1994.1001.

28. Laland KN. Exploring gene-culture interactions: insights from handedness, sexual selection and niche-construction case studies. Philos Trans R Soc Lond B Biol Sci. 2008;363(1509):3577-89. https://doi.org/10.1098/ rstb.2008.0132.

29. Lidborg LH, Cross CP, Boothroyd LG. Is male dimorphism under sexual selection in humans? A meta-analysis. bioRxiv. 2020. https://doi.org/10. 1101/2020.03.06.980896.

30. Baab KL, Freidline SE, Wang SL, Hanson T. Relationship of cranial robusticity to cranial form, geography and climate in Homo sapiens. Am J Phys Anthropol. 2010;141(1):97-115. https://doi.org/10.1002/ajpa. 21120.

31. Garvin HM, Sholts SB, Mosca LA. Sexual dimorphism in human cranial trait scores: effects of population, age, and body size. Am J Phys Anthropol. 2014;154(2):259-69. https://doi.org/10.1002/ajpa.22502.

32. Thayer ZM, Dobson SD. Geographic variation in chin shape challenges the universal facial attractiveness hypothesis. PloS one. 2013;8(4):e60681. https://doi.org/10.1371/journal.pone.0060681.

33. Tanikawa C, Zere E, Takada K. Sexual dimorphism in the facial morphology of adult humans: a three-dimensional analysis. Homo. 2016;67(1):23-49. https://doi.org/10.1016/j.jchb.2015.10.001.

34. Tanikawa C, Akcam MO, Gokalp H, Zere E, Takada K. Cross-racial consistency of sexual dimorphism in facial forms: comparisons between Turkish and Japanese populations. Sci Rep. 2021;11:16634. https://doi. org/10.21203/rs.3.rs-221121/v1.

35. Talbert L, Kau CH, Christou T, Vlachos C, Souccar N. A 3D analysis of Caucasian and African American facial morphologies in a US population. J Orthodontics. 2014;41(1):19-29. https://doi.org/10.1179/1465313313Y. 0000000077.

36. Kim JY, Kau CH, Christou T, Ovsenik M, Guk PY. Three-dimensional analysis of normal facial morphologies of asians and whites: a novel method of quantitative analysis. Plast Reconstr Surg Glob Open. 2016;4(9):e865. https://doi.org/10.1097/GOX.0000000000000853. 
37. Rostovtseva W, Mezentseva AA, Windhager S, Butovskaya ML. Sexual dimorphism in facial shape of modern Buryats of Southern Siberia. Am J Hum Biol. 2021;33(2):e23458. https://doi.org/10.1002/ajhb.23458.

38. Kleisner K, Tureček P, Roberts SC, Havlíček J, Valentova JV, Akoko RM, et al. How and why patterns of sexual dimorphism in human faces vary across the world. Sci Rep. 2021;11(1):1-14. https://doi.org/10.1038/ s41598-021-85402-3

39. Henderson AJ, Holzleitner IJ, Talamas SN, Perrett DI. Perception of health from facial cues. Philos Trans R Soc Lond B Biol Sci. 2016;371(1693):20150380. https://doi.org/10.1098/rstb.2015.0380.

40. Alonso-Alvarez C, Bertrand S, Faivre B, Chastel O, Sorci G. Testosterone and oxidative stress: the oxidation handicap hypothesis. P Roy Soc B-Biol Sci. 2007;274(1611):819-25. https://doi.org/10.1098/rspb.2006. 3764.

41. Lassek WD, Gaulin SJ. Costs and benefits of fat-free muscle mass in men: relationship to mating success, dietary requirements, and native immunity. Evol Hum Behav. 2009;30(5):322-8. https://doi.org/10.1016/j. evolhumbehav.2009.04.002

42. Pound N, Penton-Voak IS, Surridge AK. Testosterone responses to competition in men are related to facial masculinity. P Roy Soc B-Biol Sci. 2009;276(1654):153-9. https://doi.org/10.1098/rspb.2008.0990.

43. Rantala MJ, Coetzee V, Moore FR, Skrinda I, Kecko S, Krama T, et al. Facial attractiveness is related to women's cortisol and body fat, but not with immune responsiveness. Biol Lett. 2013;9(4):20130255. https://doi.org/ 10.1098/rsbl.2013.0255.

44. Akgul AA, Toygar TU. Natural craniofacial changes in the third decade of life: a longitudinal study. Am J Orthod Dentofacial Orthop. 2002;122(5):512-22. https://doi.org/10.1067/mod.2002.128861.

45. Windhager S, Schaefer K, Fink B. Geometric morphometrics of male facial shape in relation to physical strength and perceived attractiveness, dominance, and masculinity. Am J Hum Biol. 2011;23(6):805-14. https://doi.org/10.1002/ajhb.21219.

46. Mitteroecker P, Gunz P, Windhager S, Schaefer K. A brief review of shape, form, and allometry in geometric morphometrics, with applications to human facial morphology. Hystrix. 2013;24(1):59-66. https://doi.org/10. 4404/hystrix-24.1-6369.

47. Arnocky S, Hodges-Simeon CR, Ouellette D, Albert G. Do men with more masculine voices have better immunocompetence? Evol Hum Behav. 2018;39(6):602-10. https://doi.org/10.1016/j.evolhumbehav. 2018.06.003.

48. Boothroyd LG, Jones BC, Burt DM, DeBruine LM, Perrett DI. Facial correlates of sociosexuality. Evol Hum Behav. 2008;29(3):211-8. https://doi. org/10.1016/j.evolhumbehav.2007.12.009.

49. Gangestad SW, Simpson JA. The evolution of human mating: Trade-offs and strategic pluralism. Behav Brain Sci. 2000;23(4):573-87. https://doi. org/10.1017/S0140525X0000337X

50. DeBruine LM, Jones BC, Little AC, Crawford JR, Welling LL. Further evidence for regional variation in women's masculinity preferences. P Roy Soc B-Biol Sci. 2011;278(1707):813-4. https://doi.org/10.1098/rspb.2010. 2200

51. Tybur JM, Gangestad SW. Mate preferences and infectious disease: theoretical considerations and evidence in humans. Philos T Roy Soc B. 2011;366(1583):3375-88. https://doi.org/10.1098/rstb.2011.0136.

52. Puts DA, Bailey DH, Reno PL. Contest competition in men. In: Buss DM, editor. The handbook of evolutionary psychology. New Jersey: Wiley \& Sons; 2015. p. 385-402. https://doi.org/10.1002/9781119125563.evpsy ch113.

53. Sell A, Hone LS, Pound N. The importance of physical strength to human males. Hum Nat. 2012;23(1):30-44. https://doi.org/10.1007/ s12110-012-9131-2.

54. Kordsmeyer TL, Hunt J, Puts DA, Ostner J, Penke L. The relative importance of intra-and intersexual selection on human male sexually dimorphic traits. Evol Hum Behav. 2018;39(4):424-36. https://doi.org/10. 1016/j.evolhumbehav.2018.03.008.

55. Puts DA. Beauty and the beast: Mechanisms of sexual selection in humans. Evol Hum Behav. 2010;31(3):157-75. https://doi.org/10.1016/j. evolhumbehav.2010.02.005

56. Nansunga M, Manabe YC, Alele PE, Kasolo J. Association of testosterone levels with socio-demographic characteristics in a sample of Ugandan men. Afr Health Sci. 2014;14(2):348-55. https://doi.org/10.4314/ahs. v14i2.9.
57. Gapstur SM, Siscovick D, Kopp P, Colangelo L, Longcope C, Liu K. Serum androgen concentrations in young men: A longitudinal analysis of associations with age, obesity, and race.: The CARDIA male hormone study. Cancer Epidem Biomar. 2002;11(10):1041-7.

58. Campbell BC, Gray PB, Ellison PT. Age-related patterns of body composition and salivary testosterone among Ariaal men of Northern Kenya. Aging Clin Exp Res. 2006;18(6):470-6. https://doi.org/10.1007/BF033 24846.

59. Re DE, Perrett DI. Concordant preferences for actual height and facial cues to height. Pers Indiv Differ. 2012;53(7):901-6. https://doi.org/10. 1016/j.paid.2012.07.001.

60. Pawlowski B, Dunbar RI, Lipowicz A. Tall men have more reproductive success. Nature. 2000;403(6766):156. https://doi.org/10.1038/35003107.

61. Stulp G, Pollet TV, Verhulst S, Buunk AP. A curvilinear effect of height on reproductive success in human males. Behav Ecol Sociobiol. 2012;66(3):375-84. https://doi.org/10.1007/s00265-011-1283-2.

62. Pawlowski B. Variable preferences for sexual dimorphism in height as a strategy for increasing the pool of potential partners in humans. Proceedings of the Royal Society of London Series B: Biological Sciences. 2003;270(1516):709-12. https://doi.org/10.1098/rspb.2002.2294.

63. Sorokowski P, Butovskaya M. Height preferences in humans may not be universal: Evidence from the Datoga people of Tanzania. Body Image. 2012;9(4):510-6. https://doi.org/10.1016/j.bodyim.2012.07.002.

64. Sorokowski P, Sorokowska A, Butovskaya M, Stulp G, Huanca T, Fink B. Body height preferences and actual dimorphism in stature between partners in two non-Western societies (Hadza and Tsimane'). Evol Psychol. 2015;13(2):147470491501300209. https://doi.org/10.1177/14747 0491501300209.

65. Sohn K. The male-taller norm: lack of evidence from a developing country. Homo. 2015;66(4):369-78. https://doi.org/10.1016/j.jchb.2015.02. 006.

66. Stirrat M, Perrett DI. Valid facial cues to cooperation and trust: male facial width and trustworthiness. Psychological science. 2010;21(3):349_ 54. https://doi.org/10.1177/0956797610362647.

67. Geniole SN, Denson TF, Dixson BJ, Carré JM, McCormick CM. Evidence from meta-analyses of the facial width-to-height ratio as an evolved cue of threat. PloS one. 2015;10(7):e0132726. https://doi.org/10.1371/ journal.pone.0132726.

68. Huh H. Digit ratios, but not facial width-to-height ratios, are associated with the priority placed on attending to faces versus bodies. Pers Indiv Differ. 2013;54(1):133-6. https://doi.org/10.1016/j.paid.2012.08.032.

69. Huh H, Yi D, Zhu H. Facial width-to-height ratio and celebrity endorsements. Pers Indiv Differ. 2014;68:43-7. https://doi.org/10.1016/j.paid. 2014.03.044.

70. Liu Y, Kau CH, Talbert L, Pan F. Three-dimensional analysis of facial morphology. J Craniofac Surg. 2014;25(5):1890-4. https://doi.org/10.1097/ 01.SCS.0000436677.51573.a6.

71. Kramer RS. Sexual dimorphism of facial width-to-height ratio in human skulls and faces: a meta-analytical approach. Evol Hum Behav. 2017;38(3):414-20. https://doi.org/10.1016/j.evolhumbehav.2016.12. 002.

72. Hodges-Simeon CR, Albert G, Richardson GB, McHale TS, Weinberg SM, Gurven $M$, et al. Was facial width-to-height ratio subject to sexual selection pressures? A life course approach. PloS one. 2021;16(3):e0240284. https://doi.org/10.1371/journal.pone.0240284.

73. Weston EM, Friday AE, Johnstone RA, Schrenk F. Wide faces or large canines? The attractive versus the aggressive primate. P Roy Soc B-Biol Sci. 2004;271(suppl_6):S416-S9. https://doi.org/10.1098/rsbl.2004.0203.

74. Özener B. Facial width-to-height ratio in a Turkish population is not sexually dimorphic and is unrelated to aggressive behavior. Evol Hum Behav. 2012;33(3):169-73. https://doi.org/10.1016/j.evolhumbehav. 2011.08.001.

75. Kramer RS, Jones AL, Ward R. A lack of sexual dimorphism in width-toheight ratio in white European faces using 2D photographs, 3D scans, and anthropometry. Plos One. 2012;7(8):e42705. https://doi.org/10. 1371/journal.pone.0042705.

76. Lefevre CE, Lewis GJ, Bates TC, Dzhelyova M, Coetzee V, Deary IJ, et al. No evidence for sexual dimorphism of facial width-to-height ratio in four large adult samples. Evol Hum Behav. 2012;33(6):623-7. https://doi. org/10.1016/j.evolhumbehav.2012.03.002. 
77. Robertson JM, Kingsley BE. Sexually dimorphic faciometrics in black racial groups from early adulthood to late middle age. Evol Psychol. 2018;16(4):1474704918811056. https://doi.org/10.1177/1474704918 811056.

78. Robertson JM, Kingsley BE, Ford GC. Sexually dimorphic faciometrics in humans from early adulthood to late middle age: Dynamic, declining, and differentiated. Evol Psychol. 2017;15(3):1474704917730640. https:// doi.org/10.1177/1474704917730640.

79. Wen G, Zheng L. Facial width to height ratio predicts physical aggression in committed relationships in men and dominance in women in China. Pers Indiv Differ. 2020;157:109832. https://doi.org/10.1016/j.paid. 2020.109832.

80. Sell A, Cosmides L, Tooby J, Sznycer D, Von Rueden C, Gurven M. Human adaptations for the visual assessment of strength and fighting ability from the body and face. P Roy Soc B-Biol Sci. 2009;276(1656):575-84. https://doi.org/10.1098/rspb.2008.1177.

81. Zilioli S, Sell AN, Stirrat M, Jagore J, Vickerman W, Watson NV. Face of a fighter: Bizygomatic width as a cue of formidability. Aggressive Behav. 2015;41(4):322-30. https://doi.org/10.1002/ab.21544.

82. Třebický V, Fialová J, Kleisner K, Roberts SC, Little AC, Havlíček J. Further evidence for links between facial width-to-height ratio and fighting success: commentary on Zilioli et al.(2014). Aggressive Behav. 2015;41(4):331-4. https://doi.org/10.1002/ab.21559.

83. Krenn B, Meier J. Does facial width-to-height ratio predict aggressive behavior in association football? Evol Psychology. 2018;16(4):1474704918818590. https://doi.org/10.1177/1474704918 818590 .

84. Krenn B, Buehler C. Facial features and unethical behavior-doped athletes show higher facial width-to-height ratios than non-doping sanctioned athletes. PloS one. 2019;14(10):e0224472. https://doi.org/10. 1371/journal.pone.

85. Kajonius P, Eldblom H. Facial width-to-height ratio as a cue of threat: an initial event-related potential study. International Journal of Psychological and Brain Sciences. 2020;5(1):1-4. https://doi.org/10.11648/j.jppbs. 20200501.11.

86. Merlhiot G, Mondillon L, Méot A, Dutheil F, Mermillod M. Facial widthto-height ratio underlies perceived dominance on facial emotional expressions. Pers Indiv Differ. 2021;172:110583. https://doi.org/10. 1016/j.paid.2020.110583.

87. Richardson T, Bhutta A, Bantoft E, Gilman T. Neither facial aggressiveness nor facial width to height ratio are related to fighting success. PsyArXiv. 2021. https://doi.org/10.31234/osf.io/8zu6h.

88. Haselhuhn MP, Ormiston ME, Wong EM. Men's facial width-toheight ratio predicts aggression: a meta-analysis. PLoS One. 2015;10(4):e0122637. https://doi.org/10.1371/journal.pone.0122637.

89. Gómez-Valdés J, Hünemeier T, Quinto-Sánchez M, Paschetta C, de Azevedo S, González MF, et al. Lack of support for the association between facial shape and aggression: a reappraisal based on a worldwide population genetics perspective. PloS one. 2013;8(1):e52317. https://doi.org/10.1371/journal.pone.

90. Matsumoto D, Hwang HC. Facial width-to-height ratios and deception skill. Pers Indiv Differ. 2021;174:110683. https://doi.org/10.1016/j.paid. 2021.110683.

91. Weston EM, Friday AE, Liò P. Biometric evidence that sexual selection has shaped the hominin face. PloS one. 2007;2(8):e710. https://doi.org/ 10.1371/journal.pone.0000710.

92. Geniole SN, McCormick CM. Facing our ancestors: judgements of aggression are consistent and related to the facial width-to-height ratio in men irrespective of beards. Evol Hum Behav. 2015;36(4):279-85. https://doi.org/10.1371/journal.pone.0132726.

93. Stirrat M, Perrett DI. Face structure predicts cooperation: men with wider faces are more generous to their in-group when out-group competition is salient. Psychol Sci. 2012;23(7):718-22. https://doi.org/ 10.1177/0956797611435133.

94. Bowles S. Being human: Conflict: Altruism's midwife. Nature. 2008;456(7220):326-7. https://doi.org/10.1038/456326a.

95. Rusch $\mathrm{H}$. The evolutionary interplay of intergroup conflict and altruism in humans: a review of parochial altruism theory and prospects for its extension. P Roy Soc B-Biol Sci. 2014;281(1794):20141539. https://doi. org/10.1098/rspb.2014.1539.
96. Reimers L, Diekhof EK. Testosterone is associated with cooperation during intergroup competition by enhancing parochial altruism. Front Neurosci-Switz. 2015;9:183. https://doi.org/10.3389/fnins.2015.00183.

97. Wilson V, Weiss A, Lefevre CE, Ochiai T, Matsuzawa T, Inoue-Murayama $\mathrm{M}$, et al. Facial width-to-height ratio in chimpanzees: links to age, sex and personality. Evol Hum Behav. 2020;41(3):226-34. https://doi.org/10. 1016/j.evolhumbehav.2020.03.001.

98. Kramer RS. Facial width-to-height ratio in a large sample of Commonwealth Games athletes. Evol Psychol. 2015;13(1):197-209. https://doi. org/10.1177/147470491501300112.

99. Kosinski M. Facial width-to-height ratio does not predict self-reported behavioral tendencies. Psychol Sci. 2017;28(11):1675-82. https://doi. org/10.1177/0956797617716929.

100. Wang D, Nair K, Kouchaki M, Zajac EJ, Zhao X. A case of evolutionary mismatch? Why facial width-to-height ratio may not predict behavioral tendencies. Psychol Sci. 2019;30(7):1074-81.

101. Durkee PK, Ayers JD. Is facial width-to-height ratio reliably associated with social inferences? Evol Hum Behav. 2021. https://doi.org/10.1016/j. evolhumbehav.2021.06.003.

102. Bird BM, Jofré VSC, Geniole SN, Welker KM, Zilioli S, Maestripieri D, et al. Does the facial width-to-height ratio map onto variability in men's testosterone concentrations? Evol Hum Behav. 2016;37(5):392-8. https:// doi.org/10.1016/j.evolhumbehav.2016.03.004.

103. Eisenbruch AB, Lukaszewski AW, Simmons ZL, Arai S, Roney JR. Why the wide face? Androgen receptor gene polymorphism does not predict men's facial width-to-height ratio. Adaptive Human Behavior and Physiology. 2018;4(2):138-51. https://doi.org/10.1007/s40750-017-0084-x.

104. Hodges-Simeon CR, Hanson Sobraske KN, Samore T, Gurven M, Gaulin SJ. Facial width-to-height ratio ( $\mathrm{fWHR}$ ) is not associated with adolescent testosterone levels. PloS one. 2016;11(4):e0153083. https://doi.org/10. 1371/journal.pone.0153083.

105. Kordsmeyer TL, Freund D, Pita SR, Jünger J, Penke L. Further evidence that facial width-to-height ratio and global facial masculinity are not positively associated with testosterone levels. Adaptive Human Behavior and Physiology. 2019;5(2):117-30. https://doi.org/10.1007/ s40750-018-0105-4.

106. Roberts SC, Little AC, Gosling LM, Perrett DI, Carter V, Jones BC, et al. MHC-heterozygosity and human facial attractiveness. Evol Psychol. 2005;15(3):1474704917730640. https://doi.org/10.1016/j.evolhumbeh av.2004.09.002.

107. Lie HC, Rhodes G, Simmons LW. Genetic diversity revealed in human faces. Evolution. 2008;62(10):2473-86. https://doi.org/10.1111/j.15585646.2008.00478.x.

108. Rantala MJ, Moore FR, Skrinda I, Krama T, Kivleniece I, Kecko S, et al. Evidence for the stress-linked immunocompetence handicap hypothesis in humans. Nat Commun. 2012;3(1):694. https://doi.org/10.1038/ ncomms1696.

109. Phalane KG, Tribe C, Steel HC, Cholo MC, Coetzee V. Facial appearance reveals immunity in African men. Sci Rep. 2017;7(1):7443. https://doi. org/10.1038/s41598-017-08015-9.

110. Thornhill R, Gangestad SW. Facial sexual dimorphism, developmental stability, and susceptibility to disease in men and women. Evol Hum Behav. 2006;27:131-44. https://doi.org/10.1016/j.evolhumbehav.2005. 06.001.

111. Rhodes G, Chan J, Zebrowitz LA, Simmons LW. Does sexual dimorphism in human faces signal health? P Roy Soc B-Biol Sci. 2003;270(suppl_1):S93-S5. https://doi.org/10.1098/rsbl.2003.0023.

112. Nowak J, Pawłowski B, Borkowska B, Augustyniak D, Drulis-Kawa Z. No evidence for the immunocompetence handicap hypothesis in male humans. Sci Rep. 2018;8(1):1-11. https://doi.org/10.1038/ s41598-018-25694-0.

113. McDade TW, Georgiev AV, Kuzawa CW. Trade-offs between acquired and innate immune defenses in humans. Evolution, medicine, and public health. 2016;2016(1):1-16. https://doi.org/10.1093/emph/eov033.

114. Trumble BC, Blackwell AD, Stieglitz J, Thompson ME, Suarez IM, Kaplan $\mathrm{H}$, et al. Associations between male testosterone and immune function in a pathogenically stressed forager-horticultural population. Am J Phys Anthropol. 2016;161(3):494-505. https://doi.org/10.1002/ajpa.23054.

115. Melita AW, Mendlinger S. The impact of tourism revenue on the local communities' livelihood: a case study of Ngorongoro Conservation 
Area, Tanzania. Journal of Service Science and Management. 2013;6(1):117-26. https://doi.org/10.4236/jssm.2013.61012.

116. Homewood KM, Rodgers WA. Maasailand ecology: pastoralist development and wildlife conservation in Ngorongoro, Tanzania. Cambridge: Cambridge University press; 1991.

117. Spencer P. Becoming Maasai, Being in Time. In: Spear T, Waller R, editors. Being Maasai. London: James Currey; 1992. p. 140-56.

118. Butovskaya ML, Butovskiy RO. The Maasai of Tanzania: problems of sustainable development in the Ngorongoro conservation area. Siberian Historical Research. 2017;14(25):248.

119. Coast E. Maasai marriage: a comparative study of Kenya and Tanzania. J Comp Fam Stud. 2006;37(3):399-419. https://doi.org/10.3138/jcfs.37.3. 399.

120. Woodhouse E, McCabe JT. Well-being and conservation: diversity and change in visions of a good life among the Maasai of northern Tanzania. Ecol Soc. 2018;23(1). https://doi.org/10.5751/ES-09986-230143.

121. Butovskaya ML, Windhager S, Karelin D, Mezentseva A, Schaefer K, Fink B. Associations of physical strength with facial shape in an African pastoralist society, the Maasai of Northern Tanzania. PLoS One. 2018;13(5):e0197738. https://doi.org/10.1371/journal.pone.0197738.

122. Bookstein FL. Morphometric tools for landmark data: geometry and biology. Cambridge: Cambridge University Press; 1997.

123. Rohlf FJ. The tps series of software. Hystrix. 2015;26:1. https://doi.org/10. $1177 / 1474704918811056$.

124. Rostovtseva W, Mezentseva AA, Windhager S, Butovskaya ML. Secondto-fourth digit ratio and facial shape in Buryats of Southern Siberia. Early Hum Dev. 2020;149:105138. https://doi.org/10.1016/j.earlhumdev. 2020.105138.

125. Alexeev VP, Debets GF. Kraniometriya. In: Metodika antropologicheskih issledovanij [Craniometry. Method of anthropological research]. Moscow: Nauka; 1964

126. Bunak VV. Antropometriya [Anthropometry]. Moscow: State educational and pedagogical publishing house of the RSFSR People's Commissariat for Education; 1941.

127. Zelditch ML, Swiderski DL, Sheets H. Geometric morphometrics for biologists: a primer. London, Waltham, San Diego: Academic Press; 2012.

128. Oksanen J, Blanchet FG, Friendly M, Kindt R, Legendre P, McGlinn D, et al. vegan: community ecology package. R package version. 2019;2(56):2020. https://doi.org/10.1038/s41598-018-25694-0.

129. Dryden IL, Mardia KV. Statistical shape analysis, with Applications in $R$ (2nd Edition): John Wiley and Sons.; 2016.

130. Adams DC, Collyer M, Kaliontzopoulou BE. Geomorph: software for geometric morphometric analyses. R package version 3.3.2. 2021. https://cran.r-project.org/package $=$ geomorph.

131. Mitteroecker P, Gunz P. Advances in geometric morphometrics. Evol Biol. 2009;36(2):235-47. https://doi.org/10.1007/s11692-009-9055-x.

132. Team RC. R Core Team R: A language and environment for statistical computing R foundation for statistical computing. Austria, Vienna2018. URL https://www.R-project.org/.

133. Claude J. Morphometrics with R. New York: Springer Science \& Business Media; 2008.

134. Skomina Z, Verdenik M, Hren NI. Effect of aging and body characteristics on facial sexual dimorphism in the Caucasian population. PloS one. 2020;15(5):e0231983. https://doi.org/10.1371/journal.pone.0231983.

135. Zacharopoulos GV, Manios A, Kau CH, Velagrakis G, Tzanakakis GN, de Bree E. Anthropometric analysis of the face. J Craniofac Surg. 2016;27(1):e71-5. https://doi.org/10.1097/SCS.0000000000002231.

136. Boothroyd LG, Gray AW, Headland TN, Uehara RT, Waynforth D, Burt DM, et al. Male facial appearance and offspring mortality in two traditional societies. PLoS One. 2017;12(1):e0169181. https://doi.org/10.1371/journ al.pone.0169181.

137. Lidborg L, Cross C, Boothroyd L. Masculinity matters (but mostly if you're muscular): a meta-analysis of the relationships between sexually dimorphic traits in men and mating/reproductive success. bioRxiv. 2020. https://doi.org/10.1101/2020.03.06.980896.

138. Coetzee V, Faerber SJ, Greef JM, Lefevre CE, Re DE, Perrett DI. African perceptions of female attractiveness. PLoS One. 2012;7(10):e48116. https://doi.org/10.1371/journal.pone.0048116.

139. Kleisner K, Kočnar T, Tureček P, Stella D, Akoko RM, Třebický V, et al. African and European perception of African female attractiveness. Evol
Hum Behav. 2017;38(6):744-55. https://doi.org/10.1016/j.evolhumbeh av.2017.07.002.

140. Pokorný Š, Kleisner K. Sexual dimorphism in facial contrast: a case from Central Africa. Arch Sex Behav. 2021;50:3687-94. https://doi.org/10. 1007/s10508-021-01942-9.

141. Fiala V, Trebický V, Pazhoohi F, Leongómez JD, Tureček P, Saribay SA, et al. Facial attractiveness and preference of sexual dimorphism: a comparison across five populations. Evolutionary Human Sciences. 2021;3:e38. https://doi.org/10.1017/ehs.2021.33.

142. Gustafsson A, Lindenfors P. Human size evolution: no evolutionary allometric relationship between male and female stature. J Hum Evol. 2004;47(4):253-66. https://doi.org/10.1016/j.jhevol.2004.07.004.

143. Velemínská J, Bigoni L, Krajiček V, Borský J, Šmahelová D, Cagáňová V, et al. Surface facial modelling and allometry in relation to sexual dimorphism. Homo. 2012;63(2):81-93. https://doi.org/10.1016/j.jchb.2012.02. 002.

144. Geraedts EJ, Van Dommelen P, Caliebe J, Visser R, Ranke MB, Van Buuren $\mathrm{S}$, et al. Association between head circumference and body size. Horm Res Paediat. 2011;75(3):213-9. https://doi.org/10.1159/000321192.

145. Neaux D. Morphological integration of the cranium in Homo, Pan, and Hylobates and the evolution of hominoid facial structures. Am J Phys Anthropol. 2017;162(4):732-46. https://doi.org/10.1002/ajpa.23163.

146. Wagner DR, Heyward VH. Measures of body composition in blacks and whites: a comparative review. Am J Clin Nutr. 2000;71(6):1392-402. https://doi.org/10.1093/ajen/71.6.1392.

147. Kowal M, Sorokowski P, Żelaźniewicz A, Nowak J, Orzechowski S, Żurek $A$, et al. A positive relationship between body height and the testosterone response to physical exercise. Evol Hum Behav. 2021;42(3):179-85. https://doi.org/10.1016/j.evolhumbehav.2020.08.012

148. Butovskaya ML, Lazebny OE, Vasilyev VA, Dronova DA, Karelin DV, Mabulla AZ, et al. Androgen receptor gene polymorphism, aggression, and reproduction in tanzanian foragers and pastoralists. PLoS One. 2015;10(8):e0136208. https://doi.org/10.1371/journal.pone.0136208.

149. Butovskaya ML, Vasilyev VA, Lazebny OE, Suchodolskaya EM, Shibalev DV, Kulikov AM, et al. Aggression and polymorphisms in AR, DAT1, DRD2, and COMT genes in Datoga pastoralists of Tanzania. Sci Rep. 2013;3(1):3148. https://doi.org/10.1038/srep03148.

150. Butovskaya M, Sorokowska A, Karwowski M, Sabiniewicz A, Fedenok J, Dronova D, et al. Waist-to-hip ratio, body-mass index, age and number of children in seven traditional societies. Sci Rep. 2017;7(1):1-9. https:// doi.org/10.1038/s41598-017-01916-9.

151. Smith KM, Olkhov YM, Puts DA, Apicella CL. Hadza men with lower voice pitch have a better hunting reputation. Evol Psychol. 2017;15(4):1474704917740466. https://doi.org/10.1177/1474704917 740466.

152. Pisanski K, Feinberg DR. Cross-cultural variation in mate preferences for averageness, symmetry, body size, and masculinity. Cross-Cult Res. 2013;47(2):162-97. https://doi.org/10.1177/1069397112471806.

153. Little AC, DeBruine LM, Jones BC. Exposure to visual cues of pathogen contagion changes preferences for masculinity and symmetry in opposite-sex faces. P Roy Soc B-Biol Sci. 2011;278(1714):2032-9. https:// doi.org/10.1098/rspb.2010.1925.

154. Pavlovič O, Fiala V, Kleisner K. Environmental convergence in facial preferences: a cross-group comparison of Asian Vietnamese, Czech Vietnamese, and Czechs. Sci Rep. 2021;11(1):1-10. https://doi.org/10. 1038/s41598-020-79623-1.

155. Scott IM, Clark AP, Josephson SC, Boyette AH, Cuthill IC, Fried RL, et al. Human preferences for sexually dimorphic faces may be evolutionarily novel. P Natl Acad Sci USA. 2014;111(40):14388-93. https://doi.org/10. 1073/pnas.1409643111.

\section{Publisher's Note}

Springer Nature remains neutral with regard to jurisdictional claims in published maps and institutional affiliations. 